Article

\title{
Probabilistic Hesitant Intuitionistic Fuzzy Linguistic Term Sets and Their Application in Multiple Attribute Group Decision Making
}

\author{
You Peng *, Yifang Tao, Boyi Wu and Xiaoxin Wang \\ Economics and Management School, Harbin Engineering University, Harbin 150001, China; \\ Taoyifang@hrbeu.edu.cn (Y.T.); wuboyi@hrbeu.edu.cn (B.W.); xiaoxinwang@hrbeu.edu.cn (X.W.) \\ * Correspondence: pengyou@hrbeu.edu.cn
}

Received: 9 November 2020; Accepted: 20 November 2020; Published: 23 November 2020

\begin{abstract}
Multi-attribute group decision-making (MAGDM) is widely applied to various areas for solving real-life problems, including technology selection, credit assessment, strategic planning evaluation, supplier selection, etc. To describe the complex and imprecise cognition, it is more convenient to provide the decision-making information in linguistic terms rather than concrete numerical values. Thus, several linguistic models, such as the fuzzy linguistic approach (FLA), hesitant fuzzy linguistic term sets (HFLTSs), hesitant intuitionistic fuzzy linguistic term sets (HIFLTSs), and probabilistic linguistic term sets (PLTS) have been proposed successively. Due to the flexibility and comprehensiveness of PLTS, it has aroused growing concern. However, it also has a big limitation of requiring the membership degree to be 1 by default, and it does not consider the degree of non-membership and hesitancy of a linguistic variable. Therefore, the probabilistic hesitant intuitionistic fuzzy linguistic term sets (PHIFLTSs) have been presented to extend the PLTS by combining the membership and non-membership in symmetry to depict the evaluation of the experts. To overcome the existing shortcomings and enrich the methodology framework of PHIFLTSs, some novel operational laws are defined to extend the applicability and methodology of the PHIFLTSs in MAGDM. Furthermore, the distance and correlation measures for the PHIFLTSs are improved to make up the shortage of the current distance measures. In addition, the unbalanced linguistic terms are taken into account to represent the cognitive complex information of experts. At last, a MAGDM model based on the multiplicative multi-objective optimization by ratio analysis (MULTIMOORA) approach with the use of the developed novel operational laws and correlation measures is presented, which results in more accuracy and effectiveness. A real-word application example is presented to demonstrate the working of the proposed methodology. Moreover, a thorough comparison is done with related existing works in order to show the validity of this methodology.
\end{abstract}

Keywords: distance measure; similarity measurement; hesitant intuitionistic fuzzy linguistic term set; probabilistic hesitant intuitionistic fuzzy linguistic term set; multiple attribute group decision making

\section{Introduction}

Multi-attribute group decision-making (MAGDM) is usually described as the process of selecting the optimal option that has the highest degree of satisfaction from a series of finite alternatives, which are evaluated by multiple experts over multiple attributes. A complete MAGDM process can be divided into three parts: (1) expression of the evaluation values provided by a group of experts; (2) determining the weights of attributes; (3) aggregating the individual evaluations and obtaining the final ranking [1,2]. Over the past few decades, many researchers have investigated the theories and methods of MAGDM problems, and a great deal of research has been done in the fields of operational 
laws [3,4], aggregation operators [5-7], distance measures and similarity measure [8,9], and outranking relations [10-12].

In many practical situations, to describe complex and imprecise cognition, it is more convenient to provide the decision-making information in linguistic terms, such as "good" quality or "very bad" credit level, rather than precise numerical values, owing to the unquantifiable and ambiguity of the real-life condition. Zadeh [13] proposed the fuzzy linguistic approach, which adopts linguistic terms to depict the intensity of membership between an element and a set. However, experts show some hesitancy among several evaluation values, as the fuzzy linguistic approach only allows singleton linguistic term to represent the value of a linguistic variable, and thus it may not express the preference of the decision maker accurately. To improve the elicitation of linguistic information, Rodriguez et al. [14] extended the fuzzy linguistic approach and introduced hesitant fuzzy linguistic term sets (HFLTSs), which allow experts to provide their evaluations in several linguistic term values. For example, the evaluation of the new product's market prospect can be "between medium and high", and the evaluation of a supplier's service capability can be "at least good". In recent years, HFLTSs have received a great deal of attention from researchers and theories and its methods have been widely discussed [15-21].

Nevertheless, experts assume equal weight when employing each linguistic term to describe the preference intensity over HFLTSs, which may not reflect the actual conditions in some cases. For example, an expert can use $\left(s_{1}, s_{2}, s_{3}\right)$ to express his opinions and assign a weight to each linguistic term as $(0.5,0.3,0.2)$, respectively. The HFLTS fails to describe such a situation accurately due to reasons of limitations in expression. Thus, Pang et al. [22] presented probabilistic linguistic term sets (PLTSs), which not only describe the hesitant information with more than one linguistic term, but also reflect the evaluation values by assigning a weight to each linguistic term. Due to the characteristics of more flexibility and comprehensiveness, many researches have investigated the related calculation methods and extended theories. Pang et al. [22] defined the basic operations and aggregation operators for PLTS and applied them to deal with the MAGDM problems. Wu et al. [23] presented an aggregation method to obtain the collective judgement by integrating the individual opinions for PLTS. Zhang et al. [24] introduced the concept of the probabilistic linguistic preference relation (PLPR) and applied it to an investment risk assessment problem. Zhang et al. [25] investigated the consensus reaching process for MAGDM with PLPRs. Liao et al. [26] established the linear programming model of probabilistic linguistics to handle the MADM and gave an application example about evaluating the hospital levels in China.

However, PLTSs also have a big limitation for the reason of regarding the membership degree of a linguistic value to be 1 by default, and do not consider the degree of non-membership and hesitancy of a linguistic variable. However, in fact, for the reasons of cognitive limitations and knowledge gaps, this information is indispensable. A simple example of evaluating the sales of a new product can be " $60 \%$ sure high and $40 \%$ sure very high, and it cannot be bad". Therefore, Malik et al. [27] proposed probabilistic hesitant intuitionistic fuzzy linguistic term sets (PHIFLTSs), which facilitated experts to express their judgment about membership and non-membership information in linguistic terms simultaneously to cope with such complicated and ambiguous situations in the real-world.

Nevertheless, since PHIFLTSs have been put forward only a few years ago, many issues need to be solved to enrich its methodology framework.

(1) The existing PHIFLTSs proposed in [27] are based on the direct calculation between subscripts of linguistic terms and their associated probabilities. However, a great deal of important defects for these operations appear in some situations. For example, let $S=\left\{s_{t} \mid t=0,1, \ldots 6\right\}$ be a linguistic term set, $\lambda=2$ a positive real number, and $E_{s}^{1}(P)=<\left\{s_{4}(0.3), s_{5}(0.7)\right\},\left\{s_{1}(1)\right\}>$ and $E_{S}^{2}(P)=<\left\{s_{4}(1)\right\},\left\{s_{2}(1)\right\}>$ two PHIFLTSs; then, by using the operational laws given by [27], we can obtain $E_{s}^{1}(P)+E_{s}^{2}(P)=<\left\{s_{5.2}, s_{7.5}\right\},\left\{s_{3}\right\}>, \lambda E_{s}^{2}(P)=<\left\{s_{8}\right\},\left\{s_{4}\right\}>$. Obviously, the result not only exceeds the bound $\left[s_{0}, s_{6}\right]$, but also loses the associated probability information.

(2) The existing forms of PHIFLTSs are based on a qualitative scale mapped to a sequence of adjacent integers that are equally distributed. In fact, unbalanced conditions are very common if we take 
the psychology of experts into account [28]. Torra [29] discussed the unbalanced semantics for an ordered set of linguistic terms for the first time. Afterward, many achievements were obtained about the unbalanced linguistic terms [30-37]. However, Malik et al. [27] did not consider the situation of unbalanced linguistic terms on the PHIFLTS environment.

(3) The distance measure defined in [27] is also based on the subscripts of each linguistic term and the associated probability. However, on the one hand, it cannot handle the conditions of unbalanced linguistic terms over PHIFLTSs; on the other hand, unreasonable results may be produced in some specific situations.

(4) Compared with the current well-known ranking techniques including TOPSIS, VIKOR, ELECTRE, PROMETHEE, AHP, and MOORA, the multiplicative multi-objective optimization by ratio analysis (MULTIMOORA), which is specific to peculiarities of three aggregation models from the aspects of fully compensatory, non-compensatory, and incompletely compensatory has separately verified the superiority concerning time consumption, robustness, simplicity, and effectiveness [38-41]. However, advances in the state of the art have shown that no studies applied the MULTIMOORA method to the probabilistic hesitant intuitionistic fuzzy linguistic term sets environment.

To overcome the above-stated limitations and enrich the theories and methods of the PHIFLTSs, this paper focuses on the following four main aspects:

(1) This paper proposes some novel operational laws for the probabilistic hesitant intuitionistic fuzzy linguistic term sets to enrich the computation between PHIFLTSs and to improve the applicability and methodology in multi-attribute group decision-making models.

(2) This paper establishes the distance and correlation measures for the probabilistic hesitant intuitionistic fuzzy linguistic term sets, which make up for the shortage of the current distance measures.

(3) This paper takes the unbalanced linguistic terms of the probabilistic hesitant intuitionistic fuzzy linguistic term sets environment into account to better describe the difference in cognitive information of experts under different situations.

(4) This paper presents a MAGDM model based on the MULTIMOORA approach with the use of the developed novel operational laws and correlation measures.

Based on these four innovative strands of research, the following main goals of this paper are two-fold: (1) with the use of the proposed novel operational laws, distance, and correlation measure, and the unbalanced linguistic terms PHIFLTSs, to provide new theories and methods for the PHIFLTSs to overcome the existing defects; (2) with the use of the MULTIMOORA ranking approach, to propose a new multi-attribute group decision-making method for the PHIFLTSs to obtain superiority concerning time consumption, robustness, simplicity, and effectiveness at the decision making level.

The structure of this paper is as follows: Some concepts about PHIFLTSs, the normalized PHIFLTSs, intuitionistic fuzzy sets, and linguistic scale function are briefly reviewed in Section 2. Section 3 discusses the comparison between PHIFLEs. The novel operational laws for PHIFLTSs are presented in Section 4. Section 5 discusses the distance and correlation measure of the PHIFLTSs. The MAGDM method based on the MULTIMOORA approach under the PHIFLTSs environment are proposed in Section 6. An application example is presented in Section 7 to illustrate the proposed approach. Section 8 presents a comparison with some existing related methods. Our conclusions are presented in Section 9.

\section{Preliminaries}

In this section, the basic definitions and operations about probabilistic hesitant intuitionistic fuzzy linguistic term sets, intuitionistic fuzzy sets, correlation measures, and correlation coefficient are introduced. 
2.1. Probabilistic Hesitant Intuitionistic Fuzzy Linguistic Term Sets

Definition 1. [27] Let $X=\left\{x_{1}, x_{2}, \ldots, x_{n}\right\}$ be a universe of discourse, and $S=\left\{s_{i} \mid i=0,1, \ldots, g\right\}$ be a consecutive linguistic term set. A probabilistic hesitant intuitionistic fuzzy linguistic term sets on $X, E_{S}(P)$ can be mathematically represented as: $E_{S}(P)=\left\{\left(x_{i},<M_{S}^{i}(p), N_{S}^{i}(p)>\right) \mid x_{i} \in X\right\}$. Here, $M_{S}^{i}(p), N_{S}^{i}(p)$ are any subsets of $S$, respectively, which denote the membership degree and non-membership degree of linguistic variable $x_{i}$ to the linguistic term set $S$ and can be denoted as

$$
\begin{gathered}
M_{s}^{i}(p)=\left\{s_{m}^{(l)}\left(p_{m}^{(l)}\right) \mid s_{m}^{(l)} \in S, p_{m}^{(l)} \geq 0, l=1,2, \ldots, \# L_{m}, \sum_{l=1}^{\# L_{m}} p_{m}^{(l)} \leq 1\right\} \\
N_{s}^{i}(p)=\left\{s_{n}^{(l \prime)}\left(p_{n}^{(l \prime)}\right) \mid s_{n}^{(l \prime)} \in S, p_{n}^{(l \prime)} \geq 0, l \prime=1,2, \ldots, \# L_{n}, \sum_{l=1}^{L_{n}} p_{n}^{(l \prime)} \leq 1\right\}
\end{gathered}
$$

where $s_{m}^{(l)}\left(p_{m}^{(l)}\right), s_{n}^{(l)}\left(p_{n}^{(l \prime)}\right)$ are the l-th and $l^{\prime}$-th probabilistic linguistic term in $M_{S}^{i}(p), N_{s}^{i}(p), \# L_{M}, \# L_{N}$ are the number of all different linguistic terms in $M_{S}^{i}(p)$ and $N_{S}^{i}(p)$. For each PHIFLTS $E_{S}(P)$ on $X$, it should satisfy the following two conditions:

$$
s_{0} \leq \max \left(s_{m}^{(l)}\right) \oplus \min \left(s_{n}^{(l \prime)}\right) \leq s_{g} \text { and } s_{0} \leq \min \left(s_{m}^{(l)}\right) \oplus \max \left(s_{n}^{(l \prime)}\right) \leq s_{g}
$$

For convenience, $E_{S}(P)=<M_{S}(p), N_{S}(p)>$ is called the probabilistic hesitant intuitionistic fuzzy linguistic element (PHIFLE).

\subsection{The Normalization of PHIFLES}

Normally, the sum of the membership probabilities and the non-membership probabilities are both 1 in PHIFLE. However, if either of them has a sum less than 1, the normalization process should be employed to resolve it.

Definition 2. [27] Let $E_{S}(P)=\left\{\left(x_{i},<M_{S}^{i}(p), N_{S}^{i}(p)>\right) \mid x_{i} \in X\right\}$ be a PHIFLE, the normalization form of $E_{S}\left(P^{\bullet}\right)=\left\{\left(x_{i},<M_{S}^{i}\left(p^{\bullet}\right), N_{S}^{i}\left(p^{\bullet}\right)>\right) \mid x_{i} \in X\right\}$ can be defined as follows:

$$
\begin{gathered}
M_{s}^{i}\left(p^{\bullet}\right)=\left\{s_{m}^{(l)}\left(p_{m}^{\bullet(l)}\right) \mid s_{m}^{(l)} \in S, p_{m}^{\bullet(l)}=\frac{p_{m}^{(l)}}{\# L_{m}(l)}, l=1,2, \ldots, \# L_{m}, \sum_{l=1}^{\# L_{m}} p_{m}^{(l)} \leq 1\right\} \\
N_{s}^{i}\left(p^{\bullet}\right)=\left\{s_{n}^{(l \prime)}\left(p_{n}^{(\bullet l \prime)}\right) \mid s_{n}^{(l \prime)} \in S, p_{n}^{(\bullet l \prime)}=\frac{p_{n}^{(l \prime)}}{\sum_{l=1}^{\# L_{n}} p_{n}^{(l \prime)}}, l \prime=1,2, \ldots, \# L_{n}, \sum_{l \prime=1}^{\# L_{n}} p_{n}^{(l \prime)} \leq 1\right\}
\end{gathered}
$$

\subsection{Intuitionistic Fuzzy Sets and the Basic Operational Laws}

Definition 3. [42] Let $X$ be a non-empty universe of discourse and an intuitionistic fuzzy set (IFS) $A$ in $X$ is given by $A=\left\{\left\langle x, \mu_{A}(x), v_{A}(x)>: x \in X\right\}\right.$, where $\mu_{A}: X \rightarrow[0,1], v_{A}: X \rightarrow[0,1]$ with the condition $0 \leq \mu_{A}(x)+v_{A}(x) \leq 1$ for all $x \in X$. The numbers of $\mu_{A}(x)$ and $v_{A}(x)$ denote the degree of membership and non-membership of $x$ to the set $A$, respectively. IFS $(X)$ is used to denote the set of all the IFSs in X. In addition, for each $A \in \operatorname{IFS}(X), \pi_{A}(x)=1-\mu_{A}(x)-v_{A}(x)$ is termed as the indeterminacy or hesitancy degree of $x$ to the set $A$, and it is obvious that $0 \leq \pi_{A}(x) \leq 1$ for all $x \in X$.

Definition 4. [42] Let $\alpha=<\mu_{\alpha}, v_{\alpha}>, \beta=<\mu_{\beta}, v_{\beta}>$ be two intuitionistic fuzzy values (IFVs), and $\lambda$ be a positive real number; then 
(1) $\alpha \oplus \beta=<\mu_{\alpha}+\mu_{\beta}-\mu_{\alpha} \mu_{\beta}, v_{\alpha} v_{\beta}>$

(2) $\alpha \otimes \beta=<\mu_{\alpha} \mu_{\beta}, v_{\alpha}+v_{\beta}-v_{\alpha} v_{\beta}>$

(3) $\lambda \alpha=<1-\left(1-\mu_{\alpha}\right)^{\lambda}, v_{\alpha}^{\lambda}>, \lambda \geq 0$

(4) $\alpha^{\lambda}=<\mu_{\alpha}^{\lambda}, 1-\left(1-v_{\alpha}\right)^{\lambda}>, \lambda \geq 0$

(2) $\bar{\alpha}=<v_{\alpha}, v_{\beta}>$.

\subsection{Linguistic Scale Function}

The concept of linguistic scale function (LSF) can be utilized to different types of semantics of linguistic terms. Normally, the LSF $f$ is a monotonically increasing function, where $f: s_{\alpha} \rightarrow \theta_{\alpha}$; $f^{-1}: \theta_{\alpha} \rightarrow s_{\alpha}, \theta_{\alpha} \in[0,1]$. According to the different semantic distributions represented by linguistic terms, the authors in [43] defined three different types of LSFs, as follows:

(1) If the semantics of linguistic terms are divide equally, the LSF (the first type) is defined as follows:

$$
f\left(s_{i}\right)=\theta_{i}=\frac{i}{g}, \text { where } i=0,1, \ldots, g \text { and } \theta_{i} \in[0,1]
$$

(2) If the semantics of any adjacent linguistic term are unequally divided, the deviation values in every side of $s_{g / 2}$ both present the tendency of increase; the LSF (the second type) is defined as follows:

$$
f\left(s_{i}\right)=\theta_{i}= \begin{cases}\frac{a^{g / 2}-a^{(g / 2)-i}}{2 a^{g / 2}-2} & \left(i=0,1,2, \cdots, \frac{g}{2}\right) \\ \frac{a^{8 / 2}+a^{i-(g / 2)}-2}{2 a^{g / 2}-2} & \left(i=\frac{g}{2}+1, \frac{g}{2}+2, \cdots, g\right)\end{cases}
$$

If the scale level is $g+1$, then $a=\sqrt[8+1]{9}$.

(3) If the semantics of any adjacent linguistic term are unequally divided, the deviation value in every side of $s_{g / 2}$ present the tendency of decrease; the LSF (the third type) is defined as follows:

$$
f\left(s_{i}\right)=\theta_{i}= \begin{cases}\frac{(g / 2)^{\alpha}+((g / 2)-i)^{\alpha}}{2(g / 2)^{\alpha}} & \left(i=0,1,2, \cdots, \frac{g}{2}\right) \\ \frac{(g / 2)^{\beta}+(i-(g / 2))^{\beta}}{2(g / 2)^{\beta}} & \left(i=\frac{g}{2}+1, \frac{g}{2}+2, \cdots, g\right)\end{cases}
$$

where $\alpha, \beta \in(0,1]$ are determined by the decision makers based on their psychological attitudes.

\section{The Comparison between PHIFLEs}

With the aim of comparing the PHIFLEs, authors in [27] proposed the score function and the deviation degree of PHIFLTSs. However, the value of the score function defined in [27] is a linguistic term, while the score should be a crisp number, and it also cannot handle the unbalanced linguistic terms PHIFLTSs. To overcome these defects, we propose a new score function and variance value function of the PHIFLTSs in this section.

Definition 5. Let $S=\left\{s_{t} \mid t=0,1, \ldots g\right\}$ be a linguistic term set, $E_{S}(P)=<M_{S}(p), N_{S}(p)>$ be a normalized PHIFLE, and $\# L_{M}, \# L_{N}$ the total number of different linguistic elements in $M_{s}(p)$ and $N_{s}(p)$, and $f$ be the linguistic scale functions. The score function of PHIFLE can be defined as follows:

$$
S\left(E_{S}(P)\right)=\sum_{l=1}^{\# L_{M}} f\left(s_{m}^{(l)}\right) \cdot p_{m}^{(l)}-\sum_{l=1}^{\# L_{N}} f\left(s_{n}^{(l l)}\right) \cdot p_{n}^{(l \prime)}
$$

Based on Equations (2) and (3), the linguistic scale functions $f$ can be utilized to handle the conditions of unbalanced linguistic terms on the PHIFLTSs environment. For two PHIFLEs $E_{S}^{1}(P)$ and 
$E_{S}^{2}(P)$, if $S\left(E_{S}^{1}(P)\right)<S\left(E_{S}^{2}(P)\right)$, then $E_{S}^{1}(P)$ is inferior to $E_{S}^{2}(P)$; if $S\left(E_{S}^{1}(P)\right)>S\left(E_{S}^{2}(P)\right)$, then $E_{S}^{1}(P)$ is superior to $E_{S}^{2}(P)$; if $S\left(E_{S}^{1}(P)\right)=S\left(E_{S}^{2}(P)\right)$, then we cannot distinguish these two PHIFLEs. In this case, we need to define another indicator, which is the variance value function as follows:

Definition 6. Let $S=\left\{s_{t} \mid t=0,1, \ldots g\right\}$ be an LTS, $E_{S}(P)=<M_{S}(p), N_{S}(p)>$ a normalized PHIFLE, $\# L_{M}$, $\# L_{N}$ the total number of different linguistic elements in $M_{s}(p)$ and $N_{s}(p)$, and $f$ the LFS. The variance value function of PHIFLE can be defined as follows:

$$
\sigma\left(E_{S}(P)\right)=\left(\sum_{l=1}^{\# L_{M}}\left[f\left(s_{m}^{(l)}\right)-S\left(E_{S}(P)\right)\right]^{2} \cdot p_{m}^{(l)}+\sum_{l=1}^{\# L_{N}}\left[f\left(s_{n}^{(l \prime)}\right)-S\left(E_{S}(P)\right)\right]^{2} \cdot p_{n}^{(l l)}\right)^{\frac{1}{2}}
$$

For two PHIFLEs $E_{S}^{1}(P)$ and $E_{S}^{2}(P)$, if $\sigma\left(E_{S}^{1}(P)\right)<\sigma\left(E_{S}^{2}(P)\right)$, then $E_{S}^{1}(P)$ is superior to $E_{S}^{2}(P)$; if $\sigma\left(E_{S}^{1}(P)\right)>\sigma\left(E_{S}^{2}(P)\right)$, then $E_{S}^{1}(P)$ is inferior to $E_{S}^{2}(P)$; if $S\left(E_{s}^{1}(P)\right)=S\left(E_{S}^{2}(P)\right)$, then $E_{S}^{1}(P)$ is indifferent to $E_{S}^{2}(P)$.

Example 1. Let $S=\left\{s_{t} \mid t=0,1, \ldots, 6\right\}$ be an LTS, $E_{S}^{1}(P)=<\left\{s_{1}(0.5), s_{2}(0.5)\right\},\left\{s_{3}(0.3), s_{4}(0.7)\right\}>, E_{S}^{2}(P)=<$ $\left\{s_{0}(0.2), s_{1}(0.5), s_{2}(0.3)\right\},\left\{s_{3}(0.2), s_{4}(0.8)\right\}>, E_{S}^{3}(P)=<\left\{s_{0}(0.2), s_{1}(0.2), s_{2}(0.5), s_{3}(0.1),\left\{s_{3}(0.3), s_{4}(0.7)\right\}\right\}$ be three PHIFLEs. For convenience, the first type of linguistic scale function $f\left(s_{i}\right)=\frac{i}{g}, i=0,1, \ldots g$ is selected as the equivalent transformation functions $f$.

Based on Definition 5, we can obtain $S\left(E_{S}^{1}(P)\right)=-0.37, S\left(E_{S}^{2}(P)\right)=-0.447, S\left(E_{S}^{3}(P)\right)=-0.37$. Since $S\left(E_{S}^{1}(P)\right)>S\left(E_{S}^{2}(P)\right)$, then $E_{S}^{1}(P)$ is superior to $E_{S}^{2}(P)$. However, for the reason of $S\left(E_{S}^{1}(P)\right)=S\left(E_{S}^{2}(P)\right)$, we thus cannot distinguish these two PHIFLEs. Therefore, utilizing Definition 6, we can obtain $\sigma\left(E_{\mathcal{S}}^{1}(P)\right)=1.37, \sigma\left(E_{S}^{3}(P)\right)=1$.39. Since $\sigma\left(E_{\mathcal{S}}^{1}(P)\right)<\sigma\left(E_{\mathcal{S}}^{3}(P)\right)$, then $E_{\mathcal{S}}^{1}(P)$ is superior to $E_{S}^{3}(P)$.

\section{Some Novel Operational Laws of the PHIFLEs}

As aforementioned, the existing operations over PHIFLEs encounter many important defects due to the reasons of combining two different dimensions (linguistic terms and their associated probabilities) together. To consider eliminating the above-stated limitations, it is necessary to propose some novel operational laws for PHIFLEs. Inspired by [42], the linguistic scale functions $f$ and $f^{-1}$ can be viewed as a transformations tool, which make the equivalent transformations between the PHIFLEs and the IFVs possible. Utilizing the linguistic scale function $f$, the PHIFLEs are transformed to the IFVs, and then we can use the operations (Definition 4) to calculate these transformed IFVs. Furthermore, the inverse functions $f^{-1}$ can be used to transform these calculation results to the PHIFLEs equivalently. Therefore, the novel operational laws for PHIFLEs are defined:

Definition 7. Let $S=\left\{s_{t} \mid t=0,1, \ldots g\right\}$ be an LTS, $E_{S}^{1}(P)=<M_{S}^{1}(p), N_{S}^{1}(p)>, E_{S}^{2}(P)=<M_{S}^{2}(p), N_{S}^{2}(p)>$ be two normalized PHIFLEs, $f$ and $f^{-1}$ be the linguistic scale functions and the inverse functions, and $\lambda$ be a positive real number. Then

$$
\begin{aligned}
& E_{s}^{1}(P) \oplus E_{s}^{2}(P)=<f^{-1}\left\{\underset{\gamma_{1}^{(i)} \in f\left(M_{s}^{1}\right), \gamma_{2}^{(j)} \in f\left(M_{s}^{2}\right)}{U}\left(\gamma_{1}^{(i)}+\gamma_{2}^{(j)}-\gamma_{1}^{(i)} \gamma_{2}^{(j)}\right)\left(P_{1}^{(i)} P_{2}^{(j)}\right)\right\}, \\
& f^{-1}\left\{\underset{\eta_{1}^{(i)} \in f\left(N_{s}^{1}\right), \eta_{2}(j) \in f\left(N_{s}^{2}\right)}{U}\left(\eta_{1}^{(i)} \eta_{2}^{(j)}\right)\left(P_{1}^{(i)} P_{2}^{(j)}\right)\right\}>, i=1,2, \ldots, \# L_{M_{1}}, i r=1,2, \ldots, \# L_{N_{1}}, j=1,2, \ldots, \# L_{M_{2}}, j=1,2, \ldots, \# L_{N_{2}} \\
& E_{s}^{1}(P) \otimes E_{s}^{2}(P)=<f^{-1}\left\{\underset{\gamma_{1}^{(i)} \in f\left(M_{s}^{1}\right), \gamma_{2}^{(j)} \in f\left(M_{s}^{2}\right)}{U}\left(\gamma_{1}^{(i)} \gamma_{2}^{(j)}\right)\left(P_{1}^{(i)} P_{2}^{(j)}\right)\right\}, \\
& f^{-1}\left\{\underset{\eta_{1}^{(i)} \in f\left(N_{s}^{1}\right), \eta_{2}(j) \in f\left(N_{s}^{2}\right)}{U}\left(\eta_{1}^{(i)}+\eta_{2}^{(j)}-\eta_{1}^{(i)} \eta_{2}^{(j,)}\right)\left(P_{1}^{(i)} P_{2}^{(j \prime)}\right)\right\}>, i=1,2, \ldots, \# L_{M_{1}}, i l=1,2, \ldots, \# L_{N_{1}}, j=1,2, \ldots, \# L_{M_{2}}, j,=1,2, \ldots, \# L_{N_{2}}
\end{aligned}
$$

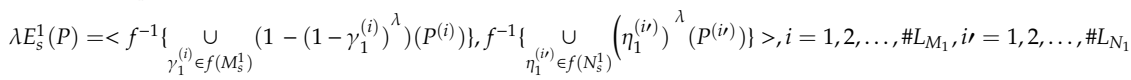

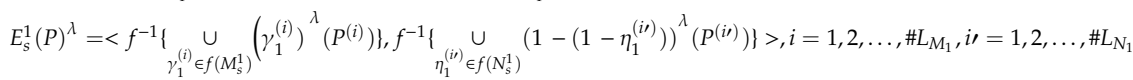


Theorem 1. Let $S=\left\{s_{t} \mid t=0,1, \ldots g\right\}$ be an LTS, $E_{S}^{1}(P)=<M_{S}^{1}(p), N_{S}^{1}(p)>, E_{S}^{2}(P)=<M_{S}^{2}(p), N_{S}^{2}(p)>$ be two PHIFLEs, and $\lambda, \lambda_{1}, \lambda_{2}$ be three positive real numbers. Then

(1) $\quad E_{S}^{1}(P) \oplus E_{S}^{2}(P)=E_{S}^{2}(P) \oplus E_{S}^{1}(P)$

(2) $\quad E_{S}^{1}(P) \otimes E_{S}^{2}(P)=E_{S}^{2}(P) \otimes E_{S}^{1}(P)$

(3) $\lambda\left(E_{S}^{1}(P) \oplus E_{\mathcal{S}}^{2}(P)\right)=\lambda E_{S}^{1}(P) \oplus \lambda E_{S}^{2}(P)$

(4) $\left(E_{S}^{1}(P) \otimes E_{S}^{2}(P)\right)^{\lambda}=\left(E_{S}^{1}(P)\right)^{\lambda} \otimes\left(E_{S}^{2}(P)\right)^{\lambda}$

Proof. (1) and (2) are obvious, and the proofs are omitted.

(3):

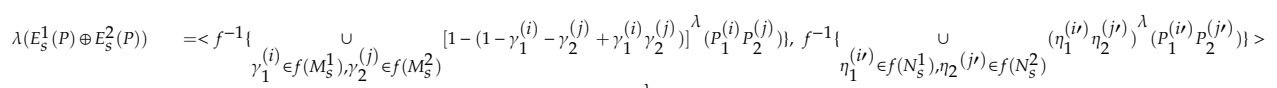

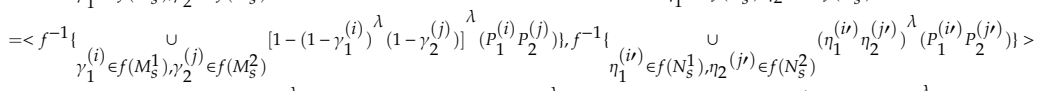

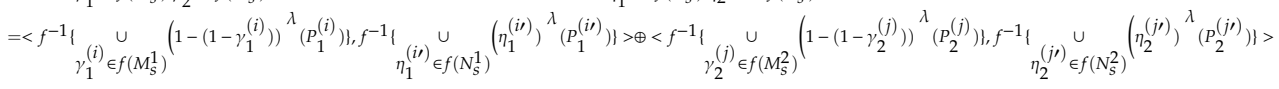

$$
\begin{aligned}
& =\lambda E_{S}^{1} \oplus \lambda E_{S}^{2}
\end{aligned}
$$

(4):

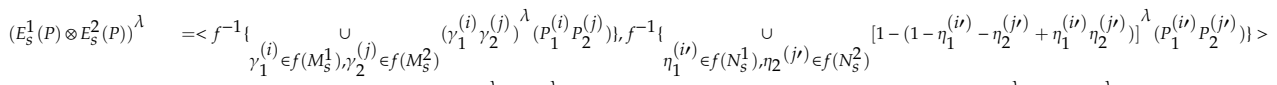

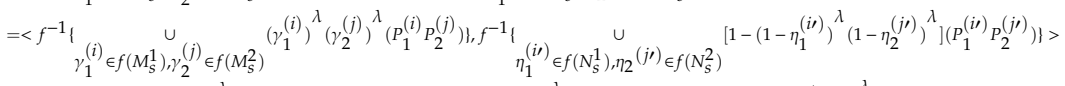

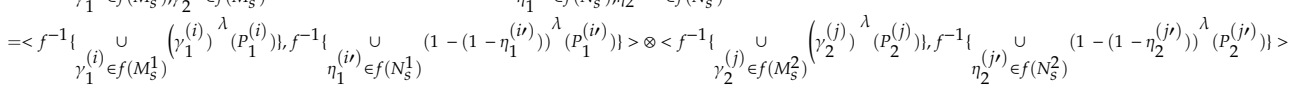

$$
\begin{aligned}
& =\left(E_{s}^{1}\right)^{\lambda} \otimes\left(E_{S}^{2}\right)^{\lambda}
\end{aligned}
$$

Example 2. Let $S=\left\{s_{t} \mid t=0,1, \ldots, 6\right\}$ be an LTS, $E_{S}^{1}(P)=<\left\{s_{1}(0.5), s_{2}(0.5)\right\},\left\{s_{3}(0.3), s_{4}(0.7)\right\}>, E_{S}^{2}(P)=<$ $\left\{s_{0}(0.2), s_{1}(0.5), s_{2}(0.3)\right\},\left\{s_{3}(0.2), s_{4}(0.8)\right\}>$ be two PHIFLEs, $\lambda=2$. For convenience, the first type of LSF $f\left(s_{i}\right)=\frac{i}{g}, i=0,1, \ldots g$ is selected as the equivalent transformation functions $f$.

Then:

Utilizing the linguistic scale functions $f$, we can obtain $f\left(M_{s}^{1}(p)\right)=\left(\frac{1}{6}, \frac{1}{3}\right)(0.5,0.5), f\left(M_{s}^{2}(p)\right)=$ $\left(0, \frac{1}{6}, \frac{1}{3}\right)(0.2,0.5,0.3), f\left(N_{s}^{1}(p)\right)=\left(\frac{1}{2}, \frac{2}{3}\right)(0.3,0.7), f\left(N_{s}^{2}(p)\right)=\left(\frac{1}{2}, \frac{2}{3}\right)(0.2,0.8)$. Then, based on Definition 7 , we can obtain the final results as follows:

$$
\begin{aligned}
& E_{s}^{1}(p) \oplus E_{s}^{2}(p)=\quad\left\langle f^{-1}\left\{\frac{2}{3}(0.1), \frac{7}{9}(0.25), \frac{8}{9}(0.15), \frac{3}{4}(0.1), \frac{5}{6}(0.25), \frac{11}{12}(0.15)\right\}, f^{-1}\left\{\frac{1}{4}(0.06), \frac{1}{3}(0.38), \frac{4}{9}(0.56)\right\}>\right. \\
& =<\left\{s_{4}(0.1), s_{4.5}(0.1), s_{4.67}(0.25), s_{5}(0.25), s_{5.33}(0.15), s_{5.5}(0.15)\right\},\left\{s_{1.5}(0.06), s_{2}(0.38), s_{2.67}(0.56)\right\}> \\
& E_{S}^{1}(p) \otimes E_{S}^{2}(p)=\left\langle f^{-1}\left\{0(0.2), \frac{1}{36}(0.25), \frac{1}{18}(0.4), \frac{1}{9}(0.15)\right\}, f^{-1}\left\{\frac{3}{4}(0.06), \frac{5}{6}(0.38), \frac{8}{9}(0.56)\right\}>\right. \\
& =<\left\{s_{0}(0.2), s_{0.17}(0.25), s_{0.33}(0.4), s_{0.67}(0.15)\right\},\left\{s_{4.5}(0.06), s_{5}(0.38), s_{5.33}(0.56)\right\}>
\end{aligned}
$$

\section{Distance and Correlation Measure of the PHIFLTSs Based on Adjusted PHIFLEs}

Distance measure can reflect the specific differences between two evaluations or sets. The existing distance measure is based on the subscripts of each linguistic term and the associated probability. However, it cannot handle the unbalanced linguistic terms PHIFLTSs and also may produce unreasonable results in some specific situations. Therefore, inspired by the method proposed in [23], we propose a new distance and correlation measure for PHIFLTSs based on adjusted PHIFLE. 


\subsection{The Adjusted PHIFLEs with Different Probability Distributions}

Usually, this is a common situation for two PHIFLEs $E_{S}^{1}(P)=<M_{S}^{1}(p), N_{S}^{1}(p)>$ and $E_{S}^{2}(P)=<$ $M_{S}^{2}(p), N_{S}^{2}(p)>$, that the number of elements in membership set and non-membership set are different, that is to say, $\# L_{M_{1}} \neq \# L_{M_{2}}$ or (and) $\# L_{N_{1}} \neq \# L_{N_{2}}$. In such situations, the existing method needs to increase the linguistic terms (the probabilities associated with the added linguistic terms are " 0 ") in the relatively shorter PHIFLE to equalize their lengths, because the PHIFLEs with different lengths bring important problems in distance measure or aggregation operators. However, on the one hand, multiplying the probabilities by the subscripts is unreasonable; on the other hand, unreasonable results may be produced.

Wu et al. [23] proposed a novel method to adjust the linguistic terms with different probability distributions. With this method, the PLEs can be adjusted to the same probability set and the operations reduced to the dimension of the linguistic terms only. Therefore, we utilized it to adjust the probability distribution on PHIFLEs.

Definition 8. [23]. Let $S=\left\{s_{t} \mid t=0,1, \ldots g\right\}$ be an LTS, $E_{S}^{1}(P)=<M_{S}^{1}(p), N_{S}^{1}(p)>, E_{S}^{2}(P)=<$ $M_{S}^{2}(p), N_{S}^{2}(p)>$ are two normalized PHIFLEs. The rearranged probability set of $M_{S}^{1}(p), M_{S}^{2}(p)$ and $N_{S}^{1}(p), N_{S}^{2}(p)$ are the same as $P^{*}=\left\{p^{*(1)}, p^{*(2)}, \ldots, p^{*(k)}\right\}$ and $P^{\bullet *}=\left\{p^{* *(1)}, p^{\bullet *(2)}, \ldots, p^{* *(k)}\right\}$. Then, the adjusted PHIFLEs are $E_{S}^{1}(P)=<M_{S}^{1}\left(p^{*}\right), N_{S}^{1}\left(p^{* *}\right)>$ and $E_{S}^{2}(P)=<M_{S}^{2}\left(p^{*}\right), N_{S}^{2}\left(p^{\bullet *}\right)>$, where

$p^{*}(1)=\min \left\{p_{1}^{(1)}, p_{2}^{(1)}\right\} \rightarrow$ if $p^{*(1)}=p_{1}^{(1)}$, then $p^{*(2)}=\min \left\{p_{1}^{(2)}, p_{2}^{(1)}-p^{*(1)}\right\}$; if $p^{*(1)}=p_{2}^{(1)}$, then $p^{*(2)}=\min \left\{p_{1}^{(1)}-p^{*(1)}, p_{2}^{(2)}\right\} \rightarrow$ if $p^{*(1)}=p_{1}^{(1)}$ and $p^{*(2)}=p_{1}^{(2)}$, then $p^{*(3)}=\min \left\{p_{1}^{(3)}, p_{2}^{(1)}-p^{*(1)}-p^{*(2)}\right\} ;$ if $p^{*(1)}=p_{2}^{(1)}$ and $p^{*(2)}=p_{2}^{(2)}$, then $p^{*(3)}=\min \left\{p_{1}^{(1)}-p^{*(1)}-p^{*(2)}, p_{2}^{(3)}\right\} ;$ if $p^{*(1)}=p_{2}^{(1)}$ and $p^{*(2)}=p_{1}^{(1)}-p^{*(1)}$, then $p^{*(3)}=\min \left\{p_{1}^{(2)}, p_{2}^{(2)}-p^{*(2)}\right\}, \ldots, p^{*(k)}=\min \left\{p_{1}^{\left(L_{m_{1}}\right)}, p_{1}^{\left(L_{m_{2}}\right)}\right\}$.

Analogously, $P^{\bullet *}=\left\{p^{\bullet *(1)}, p^{\bullet *(2)}, \ldots, p^{\bullet *(k)}\right\}$ can be obtained through the same processes. It is obvious that the linguistic terms and the sum of the associated probabilities on each linguistic term are not changed in the adjusted PHIFLE, that is to say, there is no information loss with this adjusting method.

Example 3. Let $S=\left\{s_{t} \mid t=0,1, \ldots, 6\right\}$ be an LTS, $E_{S}^{1}(P)=<\left\{s_{1}(0.5), s_{2}(0.5)\right\},\left\{s_{3}(0.3), s_{4}(0.7)\right\}>, E_{S}^{2}(P)=<$ $\left\{s_{0}(0.2), s_{1}(0.5), s_{2}(0.3)\right\},\left\{s_{3}(0.2), s_{4}(0.8)\right\}>$ be two normalized PHIFLEs.

The processes of adjusting the PHIFLEs are described in Figure 1.

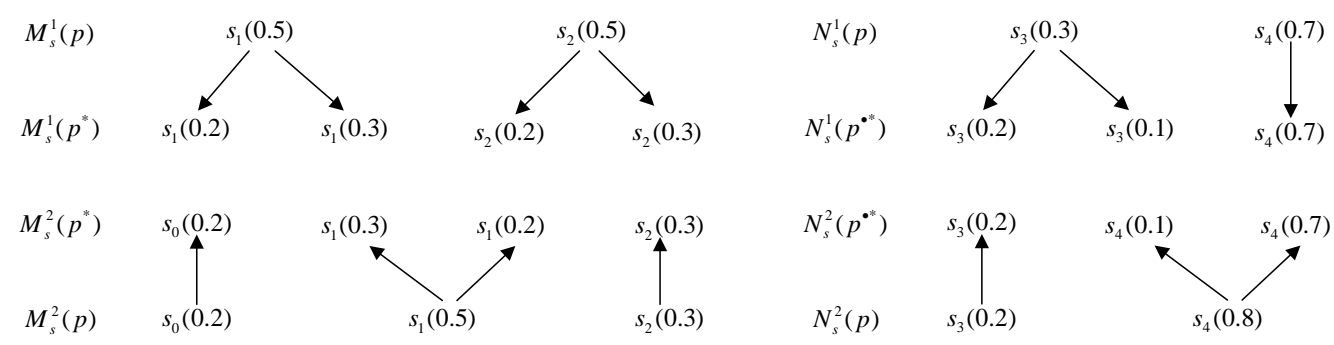

Figure 1. The process of adjusting the PHIFLEs.

\subsection{The Distance Measure of the PHIFLTSs Based on the Adjusted PHIFLEs}

The authors in [27] presented the distance measure between PHIFLEs, which is based on the aggregation of the subscript of each linguistic term and the associated probability. Nevertheless, on the one hand, it cannot handle the situations of unbalanced PHIFLTSs; on the other hand, it also encounters defects in some specific situations. Let us give an example to reveal it. 
Example 4. Let $S=\left\{s_{t} \mid t=0,1, \ldots, 6\right\}$ be an $\operatorname{LTS}, E_{S}^{1}(P)=<\left\{\left(s_{1}(0.5), s_{2}(0.5)\right)\right\},\left\{s_{4}(1)\right\}>$ and $E_{S}^{2}(P)=<$ $\left\{s_{1}(1)\right\},\left\{s_{4}(1)\right\}>$ and $E_{s}^{3}(P)=<\left\{s_{2}(0.1), s_{3}(0.9)\right\},\left\{s_{4}(1)\right\}>$ be three normalized PHIFLEs on $S$. Based on the distance measure defined in [27], we find that $d\left(E_{s}^{1}(P), E_{s}^{2}(P)\right)=0.35, d\left(E_{s}^{1}(P), E_{s}^{3}(P)\right)=1.22$, $d\left(E_{s}^{2}(P), E_{s}^{3}(P)\right)=1.21$. This implies that $E_{s}^{3}(P)$ is further to $E_{s}^{1}(P)$ than $E_{s}^{2}(P)$, which goes against the fact.

To overcome such limitations, we propose a new distance measure based on the adjusted PHIFLEs, which is defined as follows:

Definition 9. Let $S=\left\{s_{t} \mid t=0,1, \ldots g\right\}$ be a linguistic term set. $E_{S}^{1}(P)=<M_{S}^{1}(p), N_{S}^{1}(p)>$ and $E_{S}^{2}(P)=<$ $M_{S}^{2}(p), N_{S}^{2}(p)>$ be two normalized PHIFLEs on $S$; assume that the adjusted PHIFLEs are $E_{S}^{1}\left(P^{*}\right)=<$ $M_{S}^{1}\left(p^{*}\right), N_{S}^{1}\left(p^{\bullet *}\right)>$ and $E_{S}^{2}\left(P^{*}\right)=<M_{S}^{2}\left(p^{*}\right), N_{S}^{2}\left(p^{\bullet *}\right)>$, respectively. The distance $d\left(E_{S}^{1}(P), E_{S}^{2}(P)\right)$ between $E_{S}^{1}(P)$ and $E_{S}^{2}(P)$ can be defined as

$$
d\left(E_{S}^{1}(P), E_{S}^{2}(P)\right)=\left[\frac{1}{2}\left(\sum_{l=1}^{\# L_{M}} P^{(l *)}\left|f\left(s_{m}^{1(l)}\right)-f\left(s_{m}^{2(l)}\right)\right|^{\lambda}+\sum_{l=1}^{\# L_{N}} P^{(l \bullet * *)}\left|f\left(s_{n}^{1(l)}\right)-f\left(s_{n}^{2(l)}\right)\right|^{\lambda}\right)\right]^{1 / \lambda}
$$

wheres ${ }_{m}^{1(l)}, s_{m}^{2(l)}, s_{n}^{1(l)}$ and $s_{n}^{2(l \prime)}$ are the subscripts of the membership and the non-membership linguistic terms set, respectively. The linguistic scale function $f$ is determined based on the practical situations. $\lambda>0$, if $\lambda=1$, the distance measure proposed in Definition 9, is a Hamming distance measurement; if $\lambda=2$, Definition 9 is an Euclidean distance measurement.

Utilizing the proposed method in Example 4, we can obtain the Euclidean distance as $d\left(E_{S}^{1}(P), E_{s}^{2}(P)\right)=0.083, d\left(E_{s}^{1}(P), E_{S}^{3}(P)\right)=0.178, d\left(E_{S}^{2}(P), E_{S}^{3}(P)\right)=0.227$. This implies that $E_{s}^{3}(P)$ is closer to $E_{\mathcal{S}}^{1}(P)$ than $E_{\mathcal{S}}^{2}(P)$, and this is more rational.

Theorem 2. Let $S=\left\{s_{t} \mid t=0,1, \ldots g\right\}$ be a linguistic term set, and $E_{S}^{1}(P)=<M_{S}^{1}(p), N_{S}^{1}(p)>$ and $E_{S}^{2}(P)=<M_{S}^{2}(p), N_{S}^{2}(p)>$ be two PHIFLEs; the distance measure between $E_{S}^{1}(P)$ and $E_{S}^{2}(P)$ satisfies the following basic principles:

(1) $\quad d\left(E_{S}^{1}(P), E_{S}^{2}(P)\right)=d\left(E_{S}^{2}(P), E_{S}^{1}(P)\right)$

(2) $0 \leq d\left(E_{S}^{1}(P), E_{S}^{2}(P)\right) \leq 1$

(3) $d\left(E_{S}^{1}(P), E_{S}^{2}(P)\right)=0$, if and only if $E_{S}^{1}(P)=E_{S}^{2}(P)$.

\section{Proof.}

(1) It is obvious and the proof is omitted.

(2) Since $0 \leq f\left(M_{s}^{1(i)}\right) \leq 1$ and $0 \leq f\left(M_{s}^{2(i)}\right) \leq 1$, then $0 \leq\left|f\left(M_{s}^{1(i)}\right)-f\left(M_{s}^{2(i)}\right)\right|^{\lambda} \leq 1$, and thus $0 \leq \sum_{L=1}^{\# L_{M}} P^{(i *)}\left|f\left(M_{s}^{1(i)}\right)-f\left(M_{s}^{2(i)}\right)\right|^{\lambda} \leq \sum_{L=1}^{\# L_{M}} P^{(i *)}=1$. Analogously, $0 \leq \sum_{L=1}^{\# L_{N}} P^{(i / \bullet *)}\left|f\left(N_{s}^{1(i)}\right)-f\left(N_{s}^{2(i)}\right)\right|^{\lambda} \leq$ 1 , then

$0 \leq \frac{1}{2}\left(\sum_{L=1}^{\# L_{M}} P^{(i *)}\left|f\left(M_{s}^{1(i)}\right)-f\left(M_{s}^{2(i)}\right)\right|^{\lambda}+\sum_{L=1}^{\# L_{N}} P^{(i \bullet \bullet)}\left|f\left(N_{s}^{1(i)}\right)-f\left(N_{s}^{2(i)}\right)\right|^{\lambda}\right) \leq 1$, that is $0 \leq$ $d\left(E_{S}^{1}(P), E_{S}^{2}(P)\right) \leq 1$. This completes the proof of property (1).

(3) If $E_{S}^{1}(P)=E_{S}^{2}(P)$, then $f\left(s_{m}^{1(l)}\right)=f\left(s_{m}^{2(l)}\right)\left(l=1,2, \ldots, \# L_{M}\right), f\left(s_{n}^{1(l l)}\right)-f\left(s_{n}^{2(l)}\right)\left(l,=1,2, \ldots, \# L_{N}\right)$, and thus $d\left(E_{S}^{1}(P), E_{S}^{2}(P)\right)=0$. If $p^{*(k)} \geq 0(k=1,2, \ldots, K), p^{\bullet *(k)} \geq 0\left(k=1,2, \ldots, K^{\prime}\right)$, then $f\left(s_{m}^{1(l)}\right)=$ $f\left(s_{m}^{2(l)}\right)\left(l=1,2, \ldots, \# L_{M}\right), f\left(s_{n}^{1(l \prime)}\right)-f\left(s_{n}^{2(l \prime)}\right)\left(l \prime=1,2, \ldots, \# L_{N}\right)$ when $d\left(E_{S}^{1}(P), E_{S}^{2}(P)\right)=0$. Thus $E_{S}^{1}(P)=E_{S}^{2}(P)$. 


\subsection{The Correlation Measure and Correlation Coefficients of PHIFLES}

Contrary to the distance measure, the correlation measures of PHIFLEs can be regarded as the closeness degree between two variables. Normally, there are two types of methods to resolve the correlation measures, the statistics-based point of view and the information energy-based point of view. A large number of samples are the basis for the former method; however, a relatively small set of PHIFLTSs are more common for us to deal with. Therefore, we carry out the correlation measure from the views of information energy. Motivated by the studies in FSs [44], IFSs [45], HFS [46], and HFLTS [19], we propose the concept of information energy in the PHIFLTSs, which can be defined as:

Definition 10. Let $S=\left\{s_{t} \mid t=0,1, \ldots g\right\}$ be an LTS, $E_{S}(P)=\left\{\left(x_{i},<M_{S}^{i}(p), N_{S}^{i}(p)>\right) \mid x_{i} \in X\right\}$ be a normalized PHIFLTSs, and $M_{s}^{i}(p)=\left\{s_{m}^{(l)}\left(p_{m}^{(l)}\right) \mid s_{m}^{(l)} \in S, p_{m}^{(l)} \geq 0, l=1,2, \ldots, \# L_{m}\right\}, N_{s}^{i}(p)=\left\{s_{n}^{(l)}\left(p_{n}^{(l \prime)}\right) \mid s_{n}^{(l \prime)} \in S, p_{n}^{(l \prime)} \geq\right.$ $\left.0, l \prime=1,2, \ldots, \# L_{n}\right\}$, the information energy of $E_{S}(P)$ can be defined as:

$$
E_{\text {PHIFLTS }}\left(E_{S}(P)\right)=\frac{1}{2}\left(\sum_{l=1}^{L_{M}} p_{m}^{(l)}\left[f\left(s_{m}^{(l)}\right)\right]^{2}+\sum_{l=1}^{L_{N}} p_{n}^{(l \prime)}\left[f\left(s_{n}^{(l)}\right)\right]^{2}\right)
$$

where $L_{M}, L_{N}$ are the numbers of elements in $M_{S}(p)$ and $N_{s}(p)$. Then, we introduce the correlation $C_{P H I F L T S}\left(E_{S}^{1}(P), E_{S}^{2}(P)\right)$ between two PHIFLTSS $E_{S}^{1}(P)$ and $E_{S}^{2}(P)$ by the information-energy-based point of view, which can be defined as:

Definition 11. Let $S=\left\{s_{t} \mid t=0,1, \ldots g\right\}$ be a linguistic term set. For two normalized PHIFLTEs $E_{S}^{1}(P)=$ $\left\{\left(x_{i},<M_{S}^{1}(p), N_{S}^{1}(p)>\right) \mid x_{i} \in X\right\}$ and $E_{S}^{2}(P)=\left\{\left(x_{i},<M_{S}^{2}(p), N_{S}^{2}(p)>\right) \mid x_{i} \in X\right\}$, supposing that the adjusted PHIFLTEsare $E_{S}^{* 1}(P)=<M_{S}^{1}\left(p^{*}\right), N_{S}^{1}\left(p^{* *}\right)>$ and $E_{S}^{* 2}(P)=<M_{S}^{2}\left(p^{*}\right), N_{S}^{2}\left(p^{* *}\right)>$, respectively. The correlation between $E_{S}^{1}(P)$ and $E_{S}^{2}(P)$ is defined as

$$
C_{\text {PHIFLTS }}\left(E_{s}^{1}(P), E_{s}^{2}(P)\right)=\frac{1}{2}\left(\sum_{l=1}^{L_{M}} p^{(l *)}\left[f\left(s_{m}^{1(l)}\right) \cdot f\left(s_{m}^{2(l)}\right)\right]+\sum_{l=1}^{L_{N}} p^{(l \bullet * *)}\left[f\left(s_{n}^{1(l /)}\right) \cdot f\left(s_{n}^{2(l)}\right)\right]\right)
$$

With the use of the correlation and information energy, we propose the correlation coefficient between two PHIFLEs $E_{S}^{1}(P)$ and $E_{S}^{2}(P)$, which is defined as follows:

Definition 12. Let $S=\left\{s_{t} \mid t=0,1, \ldots g\right\}$ be an LTS. For two PHIFLES $E_{S}^{1}(P)=\left\{\left(x_{i},<M_{S}^{1}(p), N_{S}^{1}(p)>\right.\right.$ ) $\left.\mid x_{i} \in X\right\}$ and $E_{S}^{2}(P)=\left\{\left(x_{i},<M_{S}^{2}(p), N_{S}^{2}(p)>\right) \mid x_{i} \in X\right\}$, the correlation coefficient between $E_{S}^{1}$ and $E_{S}^{2}$ is defined as

$$
K_{\text {PHIFLTS }}\left(E_{s}^{1}(P), E_{s}^{2}(P)\right)=\frac{C_{P H I F L T S}\left(E_{s}^{1}(P), E_{s}^{2}(P)\right)}{\max \left(E_{P H I F L T S}\left(E_{s}^{1}(P)\right), E_{P H I F L T S}\left(E_{s}^{2}(P)\right)\right)}
$$

Theorem 3. Let $S=\left\{s_{t} \mid t=0,1, \ldots g\right\}$ be a linguistic term set. For two PHIFLEs $E_{S}^{1}(P)=\left\{\left(x_{i},<\right.\right.$ $\left.\left.M_{S}^{1}(p), N_{S}^{1}(p)>\right) \mid x_{i} \in X\right\}$ and $E_{S}^{2}(P)=\left\{\left(x_{i},<M_{S}^{2}(p), N_{S}^{2}(p)>\right) \mid x_{i} \in X\right\}$, the following properties of $K_{\text {PHIFLTS }}\left(E_{S}^{1}(P), E_{S}^{2}(P)\right)$ hold:

(1) $K_{\text {PHIFLTS }}\left(E_{s}^{1}(P), E_{s}^{2}(P)\right)=K_{P H I F L T S}\left(E_{s}^{2}(P), E_{s}^{1}(P)\right)$

(2) $K_{P H I F L T S}\left(E_{s}^{1}(P), E_{s}^{1}(P)\right)=1$

(3) $0 \leq K_{\text {PHIFLTS }}\left(E_{s}^{1}(P), E_{s}^{2}(P)\right) \leq 1$

Proof. (1) and (2) are obvious, and we can omit the proofs of them.

(3): According to the Cauchy inequality, 
$\left(x_{1} y_{1}+x_{2} y_{2}+\ldots+x_{n} y_{n}\right)^{2} \leq\left(x_{1}^{2}+x_{2}^{2}+\ldots+x_{n}^{2}\right) \cdot\left(y_{1}^{2}+y_{2}^{2}+\ldots+y_{n}^{2}\right)$ where $x_{i}, y_{i} \in R, i=$ $1,2, \ldots n$; we have

$$
\begin{aligned}
& \left|C_{\text {PHIFLTS }}\left(E_{s}^{1}(P), E_{s}^{2}(P)\right)\right|=\frac{1}{2}\left|\left(\sum_{l=1}^{L_{M}} p^{(l *)}\left[f\left(s_{m}^{1(l)}\right) \cdot f\left(s_{m}^{2(l)}\right)\right]+\sum_{l \nu=1}^{L_{N}} p^{(l / \bullet *)}\left[f\left(s_{n}^{1(l)}\right) \cdot f\left(s_{n}^{2(l l)}\right)\right]\right)\right| \\
& \leq \frac{1}{2} \sqrt{\sum_{l=1}^{L_{M}} p^{(l *)}\left[f\left(s_{m}^{1(l)}\right)\right]^{2}+\sum_{l=1}^{L_{N}} p^{(l \bullet * *)}\left[f\left(s_{n}^{1(l l)}\right)\right]^{2}} \cdot \sqrt{\sum_{l=1}^{L_{M}} p^{(l *)}\left[f\left(s_{m}^{2(l)}\right)\right]^{2}+\sum_{l=1}^{L_{N}} p^{(l / \bullet *)}\left[f\left(s_{n}^{2(l)}\right)\right]^{2}} \leq \max \left(E_{\text {PHIFLTS }}\left(E_{s}^{1}(P)\right), E_{P H I F L T S}\left(E_{s}^{2}(P)\right)\right)
\end{aligned}
$$

Then $\frac{\left|C_{P H I F L T S}\left(E_{s}^{1}(P), E_{s}^{2}(P)\right)\right|}{\max \left(E_{\text {PHIFLTS }}\left(E_{s}^{1}(P)\right), E_{\text {PHIFLTS }}\left(E_{S}^{2}(P)\right)\right)} \leq 1 . \quad$ Since $\quad C_{\text {PHIFLTS }}\left(E_{s}^{1}(P), E_{s}^{2}(P)\right) \geq 0$ and $E_{\text {PHIFLTS }}\left(E_{S}^{1}(P)\right), E_{P H I F L T S}\left(E_{s}^{2}(P)\right) \geq 0$, we have $0 \leq \frac{C_{P H I F L T S}\left(E_{s}^{1}(P), E_{s}^{2}(P)\right)}{\max \left(E_{P H I F L T S}\left(E_{s}^{1}(P)\right), E_{P H I F L T S}\left(E_{s}^{2}(P)\right)\right)} \leq 1$, that is $0 \leq K_{\text {PHIFLTS }}\left(E_{S}^{1}(P), E_{S}^{2}(P)\right) \leq 1$. End.

Example 5. Let $S=\left\{s_{t} \mid t=0,1, \ldots, 6\right\}$ be a linguisticterm set. $E_{S}^{1}(p)=<\left\{s_{1}(0.5), s_{2}(0.5)\right\},\left\{s_{3}(0.3), s_{4}(0.7)\right\}>$ and $E_{S}^{2}(p)=<\left\{s_{0}(0.2), s_{1}(0.5), s_{2}(0.3)\right\},\left\{s_{3}(0.2), s_{4}(0.8)\right\}>$ be two PHIFLEs.

For convenience, the $\operatorname{LSF} f\left(s_{i}\right)=\frac{i}{g}, i=0,1, \ldots g$ is selected as the equivalent transformation functions $\mathrm{f}$. The correlation coefficient between $E_{S}^{1}(p)$ and $E_{S}^{2}(p)$ can be calculated as follows:

First, based on Definition 8 we can obtain the adjusted PHIFLEs of $E_{S}^{1}(p)$ and $E_{S}^{2}(p)$ :

$$
\begin{aligned}
& E_{S}^{1}\left(p^{*}\right)=<\left\{s_{1}(0.2), s_{1}(0.3), s_{2}(0.2), s_{2}(0.3)\right\},\left\{s_{3}(0.2), s_{3}(0.1), s_{4}(0.7)\right\}> \\
& E_{S}^{2}\left(p^{*}\right)=<\left\{s_{0}(0.2), s_{1}(0.3), s_{1}(0.2), s_{2}(0.3)\right\},\left\{s_{3}(0.2), s_{4}(0.1), s_{4}(0.7)\right\}>
\end{aligned}
$$

Second, we calculate the information energy of each PHIFLE $E_{S}^{1}(p)$ and $E_{S}^{2}(p)$ based on Definition 10.

$E_{\text {PHIFLTS }}\left(E_{S}^{1}(p)\right)=\frac{1}{2}\left[0.2 \times\left(\frac{1}{6}\right)^{2}+0.3 \times\left(\frac{1}{6}\right)^{2}+0.2 \times\left(\frac{2}{6}\right)^{2}+0.3 \times\left(\frac{2}{6}\right)^{2}+0.2 \times\left(\frac{3}{6}\right)^{2}+0.1 \times\left(\frac{3}{6}\right)^{2}+0.7 \times\left(\frac{4}{6}\right)^{2}\right]=0.228$

$E_{\text {PHIFLTS }}\left(E_{S}^{2}(p)\right)=\frac{1}{2}\left[0.2 \times 0+0.3 \times\left(\frac{1}{6}\right)^{2}+0.2 \times\left(\frac{1}{6}\right)^{2}+0.3 \times\left(\frac{2}{6}\right)^{2}+0.2 \times\left(\frac{3}{6}\right)^{2}+0.1 \times\left(\frac{4}{6}\right)^{2}+0.7 \times\left(\frac{4}{6}\right)^{2}\right]=0.226$

Finally, the correlation and correlation coefficient between $E_{S}^{1}(p)$ and $E_{S}^{2}(p)$ are yielded based on Definitions 11 and 12:

$C_{\text {PHIFLTS }}\left(E_{s}^{1}(p), E_{s}^{2}(p)\right)=\frac{1}{2}\left[0.2 \times\left(\frac{1}{6} \times \frac{0}{6}\right)+0.3 \times\left(\frac{1}{6} \times \frac{1}{6}\right)+0.2 \times\left(\frac{1}{6} \times \frac{2}{6}\right)+0.3 \times\left(\frac{2}{6} \times \frac{2}{6}\right)+0.2 \times\left(\frac{3}{6} \times \frac{3}{6}\right)+0.1 \times\left(\frac{3}{6} \times \frac{4}{6}\right)+0.7 \times\left(\frac{4}{6} \times \frac{4}{6}\right)\right]=0.224$

$$
K_{\text {PHIFLTS }}\left(E_{s}^{1}(p), E_{s}^{2}(p)\right)=0.98
$$

\section{The MAGDM Method Based on the MULTIMOORA Approach under the PHIFLTSs Environment}

Based on the novel operational laws and correlation measures, we propose a new MAGDM method for the probabilistic hesitant intuitionistic fuzzy linguistic term sets utilizing the MULTIMOORA approach in this section.

\subsection{The Problem Statement}

Here, let $M=\{1,2, \ldots, m\}, N=\{1,2, \ldots, n\}, K=\{1,2, \ldots, k\} ; i \in M, j \in N, t \in K$. The multiple attribute group decision making problems considered in this paper can be represented as follows: 
Let $A=\left\{a_{1}, a_{2}, \cdots a_{m}\right\}(m \geq 2)$ be a discrete set of $m$ feasible alternatives, and $C=\left\{c_{1}, c_{2}, \cdots, c_{n}\right\}$ be a finite set of attributes. Let $D=\left\{d_{1}, d_{2}, \cdots, d_{k}\right\}$ be a group of decision makers; the individual decision matrix given by the decision maker $d_{t}(t=1,2, \ldots, k)$ are as follows:

$$
D_{t}=\left(E_{i j}^{t}(P)\right)_{m \times n}=\left(M_{i j}^{t}(P), N_{i j}^{t}(P)\right)_{m \times n}=\left[\begin{array}{ccc}
\left(M_{11}^{t}(p), N_{11}^{t}(p)\right) & \ldots & \left(M_{1 n}^{t}(p), N_{1 n}^{t}(p)\right) \\
\left(M_{21}^{t}(p), N_{21}^{t}(p)\right) & \cdots & \left(M_{2 n}^{t}(x), N_{2 n}^{t}(p)\right) \\
\vdots & \ddots & \vdots \\
\left(M_{m 1}^{t}(p), N_{m 1}^{t}(p)\right) & \cdots & \left(M_{m n}^{t}(p), N_{m n}^{t}(p)\right)
\end{array}\right]
$$

where $E_{i j}^{t}(P)$ represent the values associate with the criteria $c_{j}$ in alternative $a_{i}$ given by the decision maker $d_{t}$, which is assessed as PHIFLEs.

\subsection{Determine the Optimal Weights of Attributes Based on the TOPSIS and LP Optimization Method}

The optimal weights of attributes $w_{j}^{*}(j=1,2, \ldots, n)$ are discussed in this section. It is assumed that $C_{a t t}$ and $B_{a t t}$ are the collections of the cost attributes and the benefit attributes, respectively, such that $B_{a t t} \cap C_{a t t}=\varnothing$. For benefit attribute, the decision maker desires to have a minimum value in case of cost attribute and a maximum value among the alternatives. First, we derive the positive ideal decision (PID) $H^{+}$and the negative ideal decision (NID) $H^{-}$associated with the attribute $u_{j}(j=1,2, \ldots, n)$ as follows:

$$
\begin{aligned}
H^{+} & =\left\{\left(\max _{1 \leq i \leq m}\left\{r_{i j}\right\} \mid c_{j} \in B_{a t t}\right),\left(\min _{1 \leq i \leq m}\left\{r_{i j}\right\} \mid c_{j} \in C_{a t t}\right)\right\}=\left\{h_{1}^{+}, h_{2}^{+}, \ldots, h_{n}^{+}\right\} \\
H^{-} & =\left\{\left(\min _{1 \leq i \leq m}\left\{r_{i j}\right\} \mid c_{j} \in B_{a t t}\right),\left(\max _{1 \leq i \leq m}\left\{r_{i j}\right\} \mid c_{j} \in C_{a t t}\right)\right\}=\left\{h_{1}^{-}, h_{2}^{-}, \ldots, h_{n}^{-}\right\}
\end{aligned}
$$

where $\max \left\{r_{i j}\right\}$ and $\min \left\{r_{i j}\right\}$ can be determined based on Definitions 5 and 6. Let $\operatorname{Sim}_{i j}^{+}$and $\operatorname{Sim}_{i j}^{-}$denote the similarity measures between the $j$-th elements in the $i$-th row of the collective decision matrix and the positive ideal decision $\mathrm{H}^{+}$and the negative ideal decision $\mathrm{H}^{-}$, respectively. It can be obtained as follows:

$$
\operatorname{Sim}_{i j}^{+}=w_{j}^{*} \cdot K_{\text {PHIFLTS }}\left(r_{i j}, h_{j}^{+}\right)=w_{j}^{*} \cdot \frac{C_{\text {PHIFLTS }}\left(r_{i j}, h_{j}^{+}\right)}{\sqrt{E_{\text {PHIFLTS }}\left(r_{i j}\right)} \cdot \sqrt{E_{\text {PHIFLTS }}\left(h_{j}^{+}\right)}}
$$

where $\operatorname{Sim}_{i j}^{+} \in[0,1], i=1,2, \ldots, m, j=1,2, \ldots, n, \sum_{j=1}^{n} w_{j}^{*}=1, w_{j}^{*} \in[0,1]$.

$$
\operatorname{Sim}_{i j}^{-}=w_{j}^{*} \cdot K_{\text {PHIFLTS }}\left(r_{i j}, h_{j}^{-}\right)=w_{j}^{*} \cdot \frac{C_{\text {PHIFLTS }}\left(r_{i j}, h_{j}^{-}\right)}{\sqrt{E_{\text {PHIFLTS }}\left(r_{i j}\right)} \cdot \sqrt{E_{\text {PHIFLTS }}\left(h_{j}^{-}\right)}}
$$

where $\operatorname{Sim}_{i j}^{-} \in[0,1], i=1,2, \ldots, m, j=1,2, \ldots, n, \sum_{j=1}^{n} w_{j}^{*}=1, w_{j}^{*} \in[0,1]$.

Subsequently, the LP optimization method should be formulated to determine the $w_{j}^{*}(j=$ $1,2, \ldots, n)$. The objective function of the optimization model aims at minimizing the relative similarity from the $\mathrm{H}^{-}$and maximizing the relative similarity from the $\mathrm{H}^{+}$simultaneously.

$$
\begin{gathered}
\max \sum_{i=1}^{m} \sum_{j=1}^{n}\left(\operatorname{Sim}_{i}^{+}-\operatorname{Sim}_{i}^{-}\right) \\
\text {Subject to: }\left\{\begin{array}{l}
\sum_{j=1}^{n}\left(w_{j}^{*}\right)^{2}=1 \\
0 \leq w_{j}^{*} \leq 1, \quad j=1,2, \ldots, n
\end{array}\right.
\end{gathered}
$$




\subsection{The MULTIMOORA Approach under the PHIFLTSs Environment}

The MULTIMOORA approach is selected as the ranking techniques to solve our problem. First of all, we can calculate the scores of $R$ based on Definition 5, which is depicted as follows:

$$
S=\left(S_{i j}\right)_{m \times n}=\left(S\left(r_{i j}\right)\right)_{m \times n}
$$

The vector normalization of $S\left(E_{i j}^{t}\right)$ can be derived by

$$
S_{i j}^{N}=S_{i j} / \sqrt{\sum_{i=1}^{m}\left(S_{i j}\right)^{2}}
$$

1. Probabilistic Hesitant Intuitionistic Fuzzy Linguistic Ratio System (PHIFLRS) model

The PHIFLRS model is defined as the arithmetic weighted aggregation operator, and we can obtain the first subordinate utility value $U_{1}\left(a_{i}\right)$ of the alternative $a_{i}(i=1,2, \ldots, m)$.

$$
U_{1}\left(a_{i}\right)=\sum_{j=1}^{g} w_{j}^{*} S_{i j}^{N}-\sum_{j=g+1}^{n} w_{j}^{*} S_{i j}^{N}
$$

where $w_{j}^{*}$ are the weights of the attribute $c_{j}(j=1,2, \ldots, n) . c_{j}(j=1,2, \ldots, g)$ and $c_{j}(j=g+1, g+$ $2, \ldots, n)$ are benefit attributes and cost attributes, respectively. The alternatives $a_{i}(i=1,2, \ldots, m)$ are ranked by the value of $U_{1}\left(a_{i}\right)(i=1,2, \ldots, m)$ in descending order, and we obtain the first subordinate ranks of alternatives as $\operatorname{Rank}_{1}=\left\{a_{1}^{r 1}, a_{2}^{r 1}, \ldots, a_{n}^{r 1}\right\}$.

2. Probabilistic Hesitant Intuitionistic Fuzzy Linguistic Reference Point (PHIFLRP) model

For the reasons of avoiding the selected alternative that has poor performance under some specific attributes, we define the PHIFLRP model, which is determined by the worst performance of alternatives $a_{i}$ with respect to different attributes.

$$
U_{2}\left(a_{i}\right)=\max _{j} w_{j}^{*}\left|S_{j}^{N}-S_{i j}^{N}\right|
$$

where $S_{j}^{N}=\max _{i}\left(S_{i j}^{N}\right)$ if $c_{j}$ is a benefit attribute and $S_{j}^{N}=\min _{i}\left(S_{i j}^{N}\right)$ if $c_{j}$ is a cost attribute. The alternatives $a_{i}(i=1,2, \ldots, m)$ are ranked by the value of $U_{2}\left(a_{i}\right)(i=1,2, \ldots, m)$ in ascending order, and we obtain the second subordinate ranks of alternatives as $\operatorname{Rank}_{2}=\left\{a_{1}^{r 2}, a_{2}^{r 2}, \ldots, a_{n}^{r 2}\right\}$.

3. Probabilistic Hesitant Intuitionistic Fuzzy Linguistic Full Multiplicative Form (PHIFLFMF) model

We can obtain the third subordinate utility value $U_{3}\left(a_{i}\right)$ of the alternative $a_{i}(i=1,2, \ldots, m)$ based on the geometric weighted aggregation operator.

$$
U_{3}\left(a_{i}\right)=\prod_{j=1}^{g}\left(S_{i j}^{N}\right)^{w_{j}^{*}} / \prod_{j=g+1}^{n}\left(S_{i j}^{N}\right)^{w_{j}^{*}}
$$

where $w_{j}^{*}$ are the weights of the attribute $c_{j}(j=1,2, \ldots, n) . c_{j}(j=1,2, \ldots, g)$ and $c_{j}(j=g+1, g+$ $2, \ldots, n)$ are benefit attributes and cost attributes, respectively. The alternatives $a_{i}(i=1,2, \ldots, m)$ are ranked by the value of $U_{3}\left(a_{i}\right)(i=1,2, \ldots, m)$ in descending order, and we obtain the third subordinate ranks of alternatives as $\operatorname{Rank}_{3}=\left\{a_{1}^{r 3}, a_{2}^{r 3}, \ldots, a_{n}^{r 3}\right\}$.

At last, the above three subordinate ranks of alternatives need to be aggregated comprehensively to derive the final ranking. Since different conditions of problems are resolved by the three models, 
they can be regarded as three attributes, which are PHIFLRS $\left(C_{1}\right)$, PHIFLRP $\left(C_{2}\right)$, and PHIFLFMF $\left(C_{3}\right)$. Then, two matrices can be built based on the utility value $U_{y}\left(a_{i}\right)$ and the rank Ranky associated with each attribute $c_{y}(y=1,2,3)$, which are the utility value matrix $U=\left(U_{i j}\right)_{m \times 3}$ and the rank matrix $R K=\left(\operatorname{Rank}_{i j}\right)_{m \times 3}$.

$$
U=\left(U_{i j}\right)_{m \times 3}=\left[\begin{array}{ccc}
U_{1}\left(a_{1}\right), & U_{2}\left(a_{1}\right), & U_{3}\left(a_{1}\right) \\
U_{1}\left(a_{2}\right), & U_{2}\left(a_{2}\right), & U_{3}\left(a_{2}\right) \\
\cdot & & \\
\cdot & \cdot & \\
\cdot & & \cdot \\
U_{1}\left(a_{m}\right), & U_{2}\left(a_{m}\right), & U_{3}\left(a_{m}\right)
\end{array}\right] R K=\left(\operatorname{Rank}_{i j}\right)_{m \times 3}=\left[\begin{array}{ccc}
a_{1}^{r 1}, & a_{1}^{r 2}, & a_{1}^{r 3} \\
a_{2}^{r 1}, & a_{2}^{r 2}, & a_{2}^{r 3} \\
\cdot & & \\
\cdot & \cdot & \\
\cdot & & \cdot \\
a_{m}^{r 1}, & a_{m}^{r 2}, & a_{m}^{r 3}
\end{array}\right]
$$

In the traditional MULTIMOORA approach, the dominance theory was adopted to carry out the aggregation. However, as per the analysis in [23], this technique not only fails to consider the utility value of each alternative associated with each model but also has an extremely complex and time-consuming operation process. Therefore, inspired by the method proposed in [23], we utilized the improving Borda rule to derive the final ranking.

Firstly, the vector of these three kinds of subordinate utility value $U=\left(U_{i j}\right)_{m \times 3}$ can be normalized and derived the vector $U^{N}$ as

$$
U^{N}=\left(U_{i j}^{N}\right)_{m \times 3}=\frac{U_{j}\left(a_{i}\right)}{\sqrt{\sum_{i=1}^{m}\left(U_{j}\left(a_{i}\right)\right)^{2}}}
$$

Subsequently, we can translate the ordinal values to the scores for reasons of aggregating the cardinal of an alternative, which can be depicted as the weight of each cardinal value. The final ranking can be derived by the values of $F S_{i}$ in descending order, which is defined as

$$
F S_{i}=U_{i 1}^{N} \times \frac{m+1-a_{i}^{r 1}}{m}-U_{i 2}^{N} \times \frac{a_{i}^{r 2}}{m}+U_{i 3}^{N} \times \frac{m+1-a_{i}^{r 3}}{m}, i=1,2, \ldots m .
$$

To clarify the proposed MAGDM method based on the MULTIMOORA approach under the PHIFLTSs environment, we summarize the specific processes and describe them in Algorithm 1. 


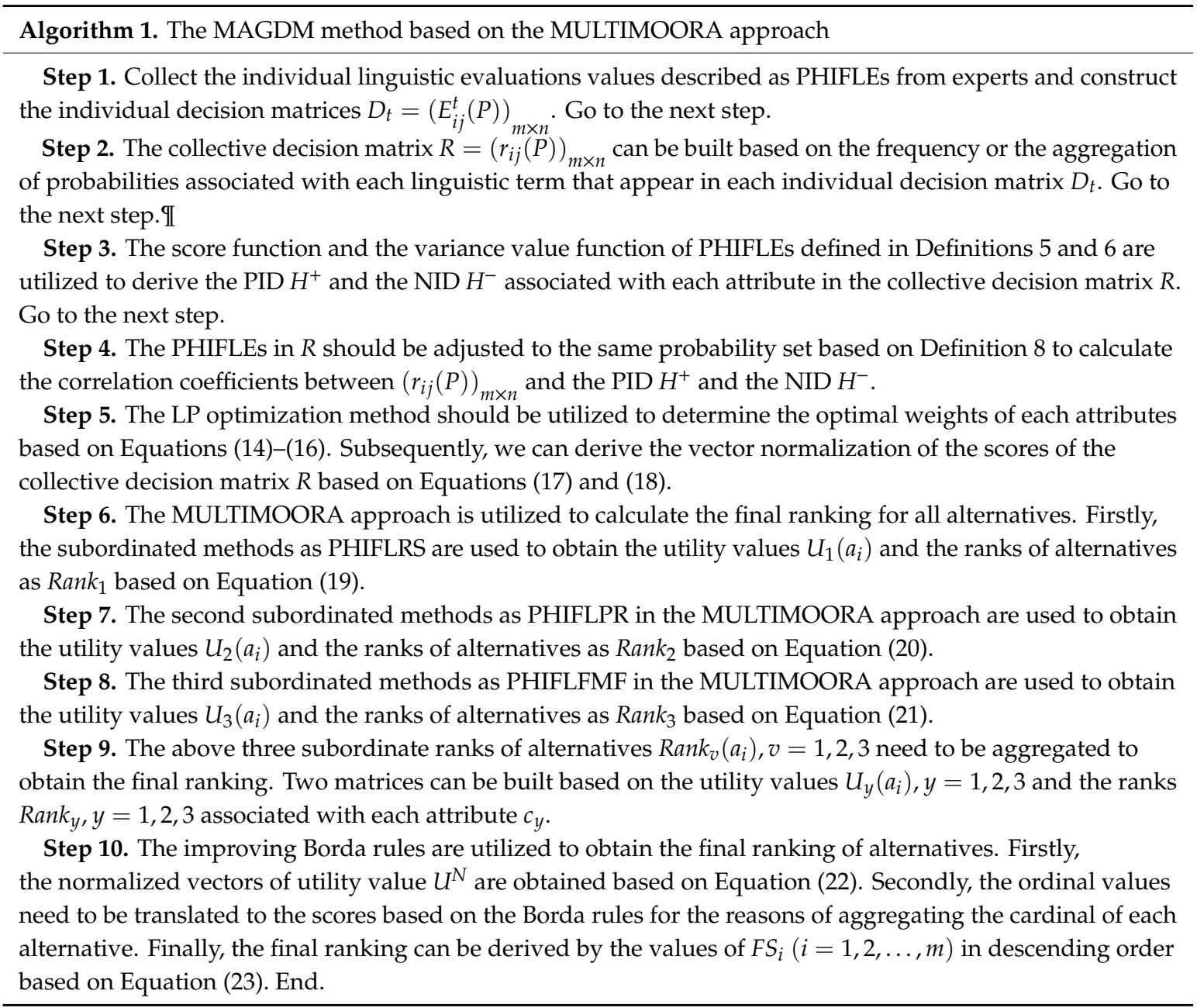

\section{Application Example}

For reasons of comparison, this part applies the same application example as [27] and [47] to validate the proposed theory and decision making models. Seven experts, denoted by $\left\{d_{1}, d_{2}, d_{3}, d_{4}, d_{5}, d_{6}, d_{7}\right\}$, need to select the most profitable method for their savings. Through interviews and surveys, four attributes, which are $c_{1}$ : Risk factor, $c_{2}$ : Growth, $c_{3}$ : Quick refund, $c_{4}$ : Complicated documents, are used to evaluate five alternatives: $x_{1}$ : Real estate, $x_{2}$ : Stock market, $x_{3}$ : T-bills, $x_{4}$ : National saving scheme, and $x_{5}$ : Insurance company.

The LTSs used on all attributes are united to $S=\left\{s_{-3}=\right.$ verybad, $s_{-2}=$ bad, $s_{-1}=$ somewhatbad, $s_{0}=$ medium, $s_{1}=$ somewhatgood, $s_{2}=$ good, $s_{3}=$ verygood $\}$. All experts assess the performance of the alternatives with respect to each attribute based on the LTS, and their opinions in terms of HIFLTSs are listed in Tables 1-3. In addition, we need to consider the semantics of unbalanced LTSs, and the second type of LSF shown as Equation (4) is selected for all attributes.

Table 1. The valuation values provided by decision makers $d_{t}(t=1,2,3)$.

\begin{tabular}{ccccc}
\hline$c_{1}$ : Risk Factor & $c_{2}$ : Growth & $c_{3}$ : Quick Refund & $\begin{array}{c}c_{4} \text { : Complicated } \\
\text { Documents } \\
\text { Requirement }\end{array}$ \\
\hline$a_{1}$ & $\left\langle\left\{s_{3}, s_{4}, s_{5}\right\},\left\{s_{1}, s_{2}\right\}\right\rangle$ & $\left\langle\left\{s_{4}, s_{5}\right\},\left\{s_{0}, s_{1}\right\}\right\rangle$ & $\left\langle\left\{s_{1}, s_{2}\right\},\left\{s_{3}, s_{4}\right\}\right\rangle$ & $\left\langle\left\{s_{1}, s_{2}\right\},\left\{s_{3}, s_{4}\right\}\right\rangle$ \\
$a_{2}$ & $\left\langle\left\{s_{1}, s_{2}\right\},\left\{s_{3}, s_{4}\right\}\right\rangle$ & $\left\langle\left\{s_{3}, s_{4}, s_{5}\right\},\left\{s_{1}, s_{2}\right\}\right\rangle$ & $\left\langle\left\{s_{3}, s_{4}\right\},\left\{s_{0}, s_{1}\right\}\right\rangle$ & $\left\langle\left\{s_{4}, s_{5}\right\},\left\{s_{1}, s_{2}\right\}\right\rangle$ \\
$a_{3}$ & $\left\langle\left\{s_{4}, s_{5}\right\},\left\{s_{0}, s_{1}, s_{2}\right\}\right\rangle$ & $\left\langle\left\{s_{3}, s_{4}\right\},\left\{s_{1}, s_{2}\right\}\right\rangle$ & $\left\langle\left\{s_{5}, s_{6}\right\},\left\{s_{0}\right\}\right\rangle$ & $\left\langle\left\{s_{1}, s_{2}\right\},\left\{s_{2}, s_{3}, s_{4}\right\}\right\rangle$ \\
$a_{4}$ & $\left\langle\left\{s_{5}, s_{6}\right\},\left\{s_{0}, s_{1}\right\}\right\rangle$ & $\left\langle\left\{s_{1}, s_{2}\right\},\left\{s_{3}, s_{4}\right\}\right\rangle$ & $\left\langle\left\{s_{1}, s_{2}\right\},\left\{s_{3}, s_{4}\right\}\right\rangle$ & $\left\langle\left\{s_{3}, s_{4}, s_{5}\right\},\left\{s_{1}, s_{2}\right\}\right\rangle$ \\
$a_{5}$ & $\left.\left\langle s_{6}\right\},\left\{s_{0}\right\}\right\rangle$ & $\left\langle\left\{s_{1}, s_{2}\right\},\left\{s_{3}, s_{4}, s_{5}\right\}\right\rangle$ & $\left\langle\left\{s_{0}, s_{1}\right\},\left\{s_{2}, s_{3}\right\}\right\rangle$ & $\left\langle\left\{s_{4}, s_{5}\right\},\left\{s_{1}, s_{2}\right\}\right\rangle$ \\
\hline
\end{tabular}


Table 2. The evaluation values provided by decision makers $d_{t}(t=4,5)$.

\begin{tabular}{ccccc}
\hline$c_{1}$ : Risk Factor & $c_{2}$ : Growth & $c_{3}$ : Quick Refund & $\begin{array}{c}c_{4} \text { : Complicated } \\
\text { Documents } \\
\text { Requirement }\end{array}$ \\
\hline$a_{1}$ & $\left\langle\left\{s_{1}, s_{2}\right\},\left\{s_{3}, s_{4}\right\}\right\rangle$ & $\left\langle\left\{s_{5}, s_{6}\right\},\left\{s_{0}, s_{1}\right\}\right\rangle$ & $\left\langle\left\{s_{0}, s_{1}\right\},\left\{s_{3}, s_{4}\right\}\right\rangle$ & $\left\langle\left\{s_{3}, s_{4}\right\},\left\{s_{1}, s_{2}\right\}\right\rangle$ \\
$a_{2}$ & $\left\langle\left\{s_{0}, s_{1}\right\},\left\{s_{2}, s_{3}\right\}\right\rangle$ & $\left\langle\left\{s_{1}, s_{2}\right\},\left\{s_{2}, s_{3}, s_{4}\right\}\right\rangle$ & $\left\langle\left\{s_{3}, s_{4}\right\},\left\{s_{0}, s_{1}\right\}\right\rangle$ & $\left\langle\left\{s_{5}, s_{6}\right\},\left\{s_{0}, s_{1}\right\}\right\rangle$ \\
$a_{3}$ & $\left\langle\left\{s_{3}, s_{4}\right\},\left\{s_{0}, s_{1}\right\}\right\rangle$ & $\left\langle\left\{s_{1}, s_{2}\right\},\left\{s_{3}, s_{4}\right\}\right\rangle$ & $\left\langle\left\{s_{4}, s_{5}\right\},\left\{s_{1}, s_{2}\right\}\right\rangle$ & $\left\langle\left\{s_{0}, s_{1}\right\},\left\{s_{2}, s_{3}\right\}\right\rangle$ \\
$a_{4}$ & $\left\langle\left\{s_{5}, s_{6}\right\},\left\{s_{0}\right\}\right\rangle$ & $\left\langle\left\{s_{3}, s_{4}\right\},\left\{s_{0}, s_{1}, s_{2}\right\}\right\rangle$ & $\left\langle\left\{s_{1}, s_{2}\right\},\left\{s_{2}, s_{3}, s_{4}\right\}\right\rangle$ & $\left\langle\left\{s_{4}, s_{5}\right\},\left\{s_{0}\right\}\right\rangle$ \\
$a_{5}$ & $\left\langle\left\{s_{4}, s_{5}\right\},\left\{s_{1}, s_{2}\right\}\right\rangle$ & $\left\langle\left\{s_{3}, s_{4}\right\},\left\{s_{1}, s_{2}, s_{3}\right\}\right\rangle$ & $\left\langle\left\{s_{1}, s_{2}\right\},\left\{s_{3}, s_{4}\right\}\right\rangle$ & $\left\langle\left\{s_{5}, s_{6}\right\},\left\{s_{0}\right\}\right\rangle$ \\
\hline
\end{tabular}

Table 3. The evaluation values provided by decision makers $d_{t}(t=6,7)$.

\begin{tabular}{ccccc}
\hline $\boldsymbol{c}_{\mathbf{1}}$ : Risk Factor & $\boldsymbol{c}_{\mathbf{2}}$ : Growth & $\boldsymbol{c}_{\mathbf{3}}$ : Quick Refund & $\begin{array}{c}\boldsymbol{c}_{\mathbf{4}} \text { : Complicated } \\
\text { Documents } \\
\text { Requirement }\end{array}$ \\
\hline$a_{1}$ & $\left\langle\left\{s_{4}, s_{5}\right\},\left\{s_{0}, s_{1}\right\}\right\rangle$ & $\left\langle\left\{s_{5}, s_{6}\right\},\left\{s_{0}\right\}\right\rangle$ & $\left\langle\left\{s_{3}, s_{4}\right\},\left\{s_{1}, s_{2}\right\}\right\rangle$ & $\left\langle\left\{s_{0}, s_{1}\right\},\left\{s_{3}, s_{4}\right\}\right\rangle$ \\
$a_{2}$ & $\left\langle\left\{s_{3}, s_{4}\right\},\left\{s_{1}, s_{2}, s_{3}\right\}\right\rangle$ & $\left\langle\left\{s_{1}, s_{2}\right\},\left\{s_{3}, s_{4}\right\}\right\rangle$ & $\left\langle\left\{s_{5}, s_{6}\right\},\left\{s_{0}\right\}\right\rangle$ & $\left\langle\left\{s_{3}, s_{4}\right\},\left\{s_{1}, s_{2}\right\}\right\rangle$ \\
$a_{3}$ & $\left\langle\left\{s_{1}, s_{2}\right\},\left\{s_{2}, s_{3}, s_{4}\right\}\right\rangle$ & $\left\langle\left\{s_{5}, s_{6}\right\},\left\{s_{0}\right\}\right\rangle$ & $\left\langle\left\{s_{4}, s_{5}\right\},\left\{s_{0}, s_{1}\right\}\right\rangle$ & $\left\langle\left\{s_{0}, s_{1}\right\},\left\{s_{3}, s_{4}\right\}\right\rangle$ \\
$a_{4}$ & $\left\langle\left\{s_{4}, s_{5}\right\},\left\{s_{1}, s_{2}\right\}\right\rangle$ & $\left\langle\left\{s_{4}, s_{5}\right\},\left\{s_{0}, s_{1}\right\}\right\rangle$ & $\left\langle\left\{s_{0}, s_{1}, s_{2}\right\},\left\{s_{2}, s_{3}\right\}\right\rangle$ & $\left\langle\left\{s_{3}, s_{4}, s_{5}\right\},\left\{s_{1}, s_{2}\right\}\right\rangle$ \\
$a_{5}$ & $\left\langle\left\{s_{3}, s_{4}\right\},\left\{s_{0}, s_{1}, s_{2}\right\}\right\rangle$ & $\left\langle\left\{s_{1}, s_{2}\right\},\left\{s_{2}, s_{3}, s_{4}\right\}\right\rangle$ & $\left\langle\left\{s_{2}, s_{3}\right\},\left\{s_{3}, s_{4}\right\}\right\rangle$ & $\left\langle\left\{s_{6}\right\},\left\{s_{0}\right\}\right\rangle$ \\
\hline
\end{tabular}

In Step 1, the HIFLEs evaluation values given by each decision maker $d_{t}(t=1,2, \ldots, 7)$ are integrated to develop the collective decision matrix $R$ based on the frequency associated with each linguistic term appearing in the individual decision matrices, the elements of which are listed in Table 4.

Table 4. The PHIFLEs collective decision matrix $R$.

\begin{tabular}{|c|c|c|}
\hline & $c_{1}:$ Risk Factor & $c_{2}:$ Growth \\
\hline \multirow[t]{2}{*}{$a_{1}$} & $\left\{s_{1}(0.12), s_{2}(0.12), s_{3}(0.18), s_{4}(0.29), s_{5}(0.29)\right\}$, & $\left\langle\left\{s_{4}(0.21), s_{5}(0.5), s_{6}(0.29)\right\},\right\rangle$ \\
\hline & $\left.\begin{array}{c}\left\{s_{0}(0.14), s_{1}(0.36), s_{2}(0.22), s_{3}(0.14), s_{4}(0.14)\right\} \\
\left\{s_{0}(0.13), s_{2}(0.25), s_{3}(0.44), s_{4}(0.18)\right\}\end{array}\right\}$ & $\left\langle\begin{array}{c}\left\{s_{1}(0.23), s_{2}(0.23), s_{3}(0.18), s_{4}(0.18), s_{5}(0.18)\right\} \\
\left\{s_{1}(0.19), s_{2}(0.31), s_{3}(0.25), s_{4}(0.25)\right\}\end{array}\right.$ \\
\hline$a_{3}$ & $\left\{s_{1}(0.14), s_{2}(0.14), s_{3}(0.14), s_{4}(0.36), s_{5}(0.22)\right\}$ & $\left\{s_{1}(0.14), s_{2}(0.14), s_{3}(0.22), s_{4}(0.22), s_{5}(0.14), s_{6}(0.14)\right\}$ \\
\hline$u_{3}$ & $\begin{array}{c}\left|\left\{s_{0}(0.26), s_{1}(0.26), s_{2}(0.26), s_{3}(0.11), s_{4}(0.11)\right\}\right| \\
\left|\left\{s_{4}(0.14), s_{5}(0.5), s_{5}(0.36)\right\},\right|\end{array}$ & $\backslash \quad \begin{array}{l}\left\{s_{0}(0.17), s_{1}(0.25), s_{2}(0.25), s_{3}(0.17), s_{4}(0.16),\right\} \\
\mid\left\{s_{1}(0.21), s_{2}(0.21), s_{3}(0.14), s_{4}(0.3), s_{5}(0.14)\right\},\end{array}$ \\
\hline$a_{4}$ & $\left|\left\{s_{0}(0.42), s_{1}(0.42), s_{2}(0.16)\right\}\right|$ & $\left\{s_{0}(0.25), s_{1}(0.25), s_{2}(0.12), s_{3}(0.19), s_{4}(0.19)\right\}$ \\
\hline \multirow[t]{2}{*}{$a_{5}$} & $\left.\begin{array}{c}\left\{s_{3}(0.18), s_{4}(0.36), s_{5}(0.18), s_{6}(0.28)\right\} \\
\left\{s_{0}(0.38), s_{1}(0.31), s_{2}(0.31)\right\}\end{array}\right\}$ & $\left\langle\begin{array}{c}\left\{s_{1}(0.36), s_{2}(0.36), s_{3}(0.14), s_{4}(0.14)\right\} \\
\left\{s_{1}(0.1), s_{2}(0.19), s_{3}(0.33), s_{4}(0.24), s_{5}(0.14)\right\}\end{array}\right\rangle^{\prime}$ \\
\hline & $c_{3}$ : Quick Refund & $c_{4}$ : Complicated Documents Requirement \\
\hline$a_{1}$ & $\left|\begin{array}{c}\left\{s_{0}(0.14), s_{1}(0.36), s_{2}(0.22), s_{3}(0.14), s_{4}(0.14)\right\} \\
\left\{s_{1}(0.14), s_{2}(0.14), s_{3}(0.36), s_{4}(0.36)\right\}\end{array}\right\rangle$ & $\left\langle\begin{array}{c}\left\{s_{0}(0.14), s_{1}(0.36), s_{2}(0.22), s_{3}(0.14), s_{4}(0.14)\right\}, \\
\left\{s_{1}(0.14), s_{2}(0.14), s_{3}(0.36), s_{4}(0.36)\right\}\end{array}\right\rangle$ \\
\hline$a_{2}$ & $\left\langle\begin{array}{c}\left\{s_{3}(0.21), s_{4}(0.36), s_{5}(0.29), s_{6}(0.14)\right\} \\
\left\{s_{0}(0.58), s_{1}(0.42)\right\}\end{array}\right\rangle$ & $\left\langle\begin{array}{c}\left\{s_{3}(0.14), s_{4}(0.36), s_{5}(0.36), s_{6}(0.14)\right\} \\
\left\{s_{0}(0.16), s_{1}(0.42), s_{2}(0.42)\right\}\end{array}\right\rangle$ \\
\hline$a_{3}$ & $\left\langle\begin{array}{l}\left\{s_{4}(0.29), s_{5}(0.5), s_{6}(0.21)\right\} \\
\left\{s_{0}(0.46), s_{1}(0.36), s_{2}(0.18)\right\}\end{array}\right\rangle$ & $\left\langle\begin{array}{l}\left\{s_{0}(0.29), s_{1}(0.5), s_{2}(0.21)\right\} \\
\left\{s_{2}(0.29), s_{3}(0.41), s_{4}(0.3)\right\}\end{array}\right)$ \\
\hline$a_{4}$ & $\left\langle\begin{array}{l}\left\{s_{0}(0.12), s_{1}(0.44), s_{2}(0.44\}\right. \\
\left\{s_{2}(0.25), s_{3}(0.44), s_{4}(0.31)\right\}\end{array}\right\}$ & $\left.\begin{array}{l}\left\{s_{3}(0.26), s_{4}(0.37), s_{5}(0.37)\right\} \\
\left\{s_{0}(0.16), s_{1}(0.42), s_{2}(0.42)\right\}\end{array}\right\}$ \\
\hline$a_{5}$ & $\left\{\begin{array}{c}\left\{s_{0}(0.21), s_{1}(0.36), s_{2}(0.29), s_{3}(0.14)\right\} \\
\left\{s_{2}(0.21), s_{3}(0.5), s_{4}(0.29)\right\}\end{array}\right\}$ & $\left\{\begin{array}{c}\left\{s_{4}(0.25), s_{5}(0.42), s_{6}(0.33)\right\} \\
\left\{s_{0}(0.4), s_{1}(0.3), s_{2}(0.3)\right\}\end{array}\right.$ \\
\hline
\end{tabular}

In Step 2, for reasons of comparison between PHIFLEs, the score function and the variance value function of PHIFLE defined in Definitions 5 and 6 are utilized to obtain the positive ideal decision $\mathrm{H}^{+}$and the negative ideal decision $\mathrm{H}^{-}$associated with each attribute $c_{j}(j=1,2,3,4)$ in the collective decision matrix $R$, which are listed in Tables 5 and 6. 
Table 5. The score of the collective decision matrix $R$.

\begin{tabular}{ccccc}
\hline & $c_{\mathbf{1}}$ : Risk Factor & $\boldsymbol{c}_{\mathbf{2}}$ : Growth & $\boldsymbol{c}_{\mathbf{3}}$ : Quick Refund & $\begin{array}{c}\boldsymbol{c}_{\mathbf{4}} \text { : Complicated } \\
\text { DocumentsRequirement }\end{array}$ \\
\hline$a_{1}$ & 0.2478 & 0.7168 & -0.1667 & -0.1667 \\
$a_{2}$ & -0.1354 & 0.0406 & 0.6005 & 0.4595 \\
$a_{3}$ & 0.2690 & 0.2448 & 0.6303 & -0.3104 \\
$a_{4}$ & 0.6800 & 0.1776 & -0.2416 & 0.3934 \\
$a_{5}$ & 0.5466 & -0.1434 & -0.2490 & 0.6307 \\
\hline
\end{tabular}

Table 6. The PID $H^{+}$and the NID $H^{-}$associated with each attribute $c_{j}(j=1,2,3,4)$.

\begin{tabular}{|c|c|c|}
\hline & $c_{1}:$ Risk Factor & $c_{2}:$ Growth \\
\hline $\mathrm{H}^{+}$ & $\begin{array}{c}\left\{s_{0}(0.14), s_{1}(0.36), s_{2}(0.22), s_{3}(0.14), s_{4}(0.14)\right\} \\
\left\{s_{1}(0.13), s_{2}(0.25), s_{3}(0.44), s_{4}(0.18)\right\}\end{array}$ & $\left\langle\begin{array}{c}\left\{s_{4}(0.21), s_{5}(0.5), s_{6}(0.29)\right\}, \\
\left\{s_{0}(0.58), s_{1}(0.42)\right\}\end{array}\right\rangle$ \\
\hline \multirow[t]{2}{*}{$\mathrm{H}^{-}$} & $\left\langle\begin{array}{l}\left\{s_{4}(0.14), s_{5}(0.5), s_{5}(0.36)\right\} \\
\left\{s_{0}(0.42), s_{1}(0.42), s_{2}(0.16)\right\}\end{array}\right\rangle$ & $\left.\begin{array}{c}\left\{s_{1}(0.36), s_{2}(0.36), s_{3}(0.14), s_{4}(0.14)\right\} \\
\left\{s_{1}(0.1), s_{2}(0.19), s_{3}(0.33), s_{4}(0.24), s_{5}(0.14)\right\}\end{array}\right\}$ \\
\hline & $c_{3}:$ Quick Refund & $c_{4}$ : Complicated Documents Requirement \\
\hline $\mathrm{H}^{+}$ & $\left\langle\begin{array}{l}\left\{s_{4}(0.29), s_{5}(0.5), s_{6}(0.21)\right\} \\
\left\{s_{0}(0.46), s_{1}(0.36), s_{2}(0.18)\right\}\end{array}\right\rangle$ & $\left\langle\begin{array}{l}\left\{s_{0}(0.29), s_{1}(0.5), s_{2}(0.21)\right\}, \\
\left\{s_{2}(0.29), s_{3}(0.41), s_{4}(0.3)\right\}\end{array}\right\rangle$ \\
\hline $\mathrm{H}^{-}$ & $\left.\begin{array}{c}\left\{s_{0}(0.21), s_{1}(0.36), s_{2}(0.29), s_{3}(0.14)\right\} \\
\left\{s_{2}(0.21), s_{3}(0.5), s_{4}(0.29)\right\}\end{array}\right\}$ & $\left\langle\begin{array}{c}\left\{s_{4}(0.25), s_{5}(0.42), s_{6}(0.33)\right\} \\
\left\{s_{0}(0.4), s_{1}(0.3), s_{2}(0.3)\right\}\end{array}\right\rangle$ \\
\hline
\end{tabular}

In Step 3, to calculate the correlation coefficients between the collective decision matrix $R$ and the PID $H^{+}$and the NID $H^{-}$for all the alternatives $a_{i}(i=1,2, \ldots, 5)$, the PHIFLEs should be adjusted to the same probability set based on Definition 8 .

In Step 4, Equations (14) and (15) are utilized to calculate the similarity $\operatorname{Sim}_{i}^{+}$and $\operatorname{Sim}_{i}^{-}$between the adjusted PHIFLEs of the collective decision matrix $R$ and the PID $H^{+}$and the NID $H^{-}$for all alternatives $a_{i}(i=1,2, \ldots, 5)$, which are listed in Tables 7 and 8 .

Table 7. The similarity $\operatorname{Sim}_{i}^{+}$between the adjusted PHIFLEs of $R$ and the PID $H^{+}$.

\begin{tabular}{ccccc}
\hline$c_{\mathbf{1}}$ : Risk Factor & $\boldsymbol{c}_{\mathbf{2}}$ : Growth & $\boldsymbol{c}_{\mathbf{3}}$ : Quick Refund & $\begin{array}{c}\boldsymbol{c}_{\mathbf{4}} \text { : Complicated } \\
\text { Documents } \\
\text { Requirement }\end{array}$ \\
\hline$a_{1}$ & 0.7706 & 1 & 0.5357 & 0.8597 \\
$a_{2}$ & 1 & 0.9693 & 0.8759 & 0.4729 \\
$a_{3}$ & 0.7855 & 0.7877 & 1 & 1 \\
$a_{4}$ & 0.4935 & 0.6771 & 0.4553 & 0.0676 \\
$a_{5}$ & 0.5842 & 0.5479 & 0.4637 & 0.3739 \\
\hline
\end{tabular}

Table 8. The similarity $\operatorname{Sim}_{i}^{-}$between the adjusted PHIFLEs of $R$ and the NID $H^{-}$.

\begin{tabular}{ccccc}
\hline$c_{1}$ : Risk Factor & $c_{2}$ : Growth & $c_{3}$ : Quick Refund & $\begin{array}{c}c_{4} \text { : Complicated } \\
\text { Documents } \\
\text { Requirement }\end{array}$ \\
\hline$a_{1}$ & 0.7475 & 0.5479 & 0.6766 & 0.5277 \\
$a_{2}$ & 0.4935 & 0.9637 & 0.3791 & 0.8866 \\
$a_{3}$ & 0.7011 & 0.7938 & 0.4637 & 0.1636 \\
$a_{4}$ & 1 & 0.7377 & -0.2416 & 0.1636 \\
$a_{5}$ & 0.8995 & 1 & 1 & 1 \\
\hline
\end{tabular}

In Step 5, the LP optimization method is utilized to determine the optimal weights of the attributes $c_{j}(j=1,2,3,4)$ based on Equation $(16)$, which is $w_{j}^{*}=(0.2653,0.2848,0.2310,0.2189)$. 
In Step 6, based on Equations (17) and (18), we can obtain the vector normalization of the scores of the collective decision matrix $R$.

In Step 7, the MULTIMOORA approach is utilized to calculate the final ranking for all alternatives $a_{i}(j=1,2 \ldots, 5)$. Firstly, the subordinated methods as PHIFLRS are used to obtain the utility values $U_{1}\left(a_{i}\right)=(0.1872,0.0911,0.2384,-0.275,-0.41)$ and the ranks of alternatives as $\operatorname{Rank}_{1}=(2,3,1,4,5)$ based on Equation (19).

In Step 8, the second subordinated methods as PHIFLPR in the MULTIMOORA approach are used to obtain the utility values $U_{2}\left(a_{i}\right)=(0.1934,0.2431,0.1697,0.2263,0.3039)$ and the ranks of alternatives as Rank $_{1}=(2,3,1,4,5)$ based on Equation (20).

In Step 9, the third subordinated methods as PHIFLFMF in the MULTIMOORA approach are used to obtain the utility values $U_{3}\left(a_{i}\right)=(1.1036,1.0606,1.2139,0.7781,0.6832)$ and the ranks of alternatives as $\operatorname{Rank}_{3}=(2,3,1,4,5)$ based on Equation (21).

In Step 10, the above three subordinate ranks of alternatives $\operatorname{Rank}_{v}\left(a_{i}\right), v=1,2,3 ; i=1,2, \ldots, 5$ need to be aggregated to obtain the final ranking. Two matrices can be built based on the utility values $U_{y}\left(a_{i}\right), y=1,2,3 ; i=1,2, \ldots, 5$ and the ranks $\operatorname{Rank}_{y}, y=1,2,3 ; i=1,2, \ldots, 5$ associated with each attribute $c_{y}(y=1,2,3)$, which are listed as follows.

$$
U=\left(U_{i j}\right)_{5 \times 3}=\left[\begin{array}{c}
0.1872,0.1934,1.1036 \\
0.0911,0.2431,1.0606 \\
0.2384,0.1697,1.2139 \\
-0.275,0.2263,0.7781 \\
-0.410,0.3093,0.6832
\end{array}\right] R K=\left(\operatorname{Rank}_{i j}\right)_{5 \times 3}=\left[\begin{array}{ccc}
2, & 2, & 2 \\
3, & 4, & 3 \\
1, & 1, & 1 \\
4, & 3, & 4 \\
5, & 5, & 5
\end{array}\right]
$$

In Step 11, the improving Borda rules are utilized to derive the final ranking of alternatives $a_{i}$ $(i=1,2, \ldots, 5)$. Firstly, the normalized vectors of utility value $U^{N}$ are obtained based on Equation (22). Secondly, the ordinal values need to be translated to the scores based on the Borda rules for reasons of aggregating the cardinal of each alternative. Finally, the final ranking can be derived by the values of $F S_{i}(i=1,2, \ldots, m)$ in descending order based on Equation (23), which are listed in Table 9.

Table 9. The final score and ranking of alternatives $a_{i}(i=1,2, \ldots, m)$.

\begin{tabular}{cccccc}
\hline $\mathbf{c}$ & $a_{1}$ & $a_{2}$ & $a_{3}$ & $a_{4}$ & $a_{5}$ \\
\hline FS & 0.5063 & 0.0082 & 0.8904 & -0.3070 & -0.6708 \\
Ranking & \multicolumn{5}{c}{$a_{3}>a_{1}>a_{2}>a_{4}>a_{5}$} \\
\hline
\end{tabular}

\section{Comparison with Other Related Research Works}

In this section, we present a comparison with the existing related works to show the advantages and innovation of the proposed method.

\subsection{Comparative Analysis from the Numerical Points with the existing method}

The authors in [27] firstly defined the PHIFLTSs and the corresponding application in MAGDM. The proposed method in this paper differs from the approach in [27] with respect to the following points:

(1) The operations over PHIFLTSs proposed in [27] are directly based on multiplying the probabilities by the subscript of the corresponding linguistic terms, which may lose the associated probability information. For example, the PIS and NIS obtained in [27] are $(\langle\{3,3\},\{0,0\}\rangle,\langle\{3,2.4\},\{0,0\}\rangle, \ldots)$ and $(\langle\{0,0.661\},\{2.25,1\}\rangle,\langle\{1,1\},\{2.25,1.25\}\rangle, \ldots)$; however, the PIS $H^{+}$and NIS $H^{-}$obtained in this paper are $\left\langle\left\{s_{0}(0.14), s_{1}(0.36), s_{2}(0.22), s_{3}(0.14), s_{4}(0.14)\right\}, \ldots\right\rangle$ and $\left\langle\left\{s_{4}(0.29), s_{5}(0.5), s_{6}(0.21)\right\}, \ldots\right\rangle$. Obviously, the former one loses the probability information, which may lead to the failure of the final decision-making; 
(2) The method in [27] does not consider the situations of unbalanced linguistic terms on the PHIFLTSs environment; however, this paper selects the second type of linguistic scale function for all attributes to deal with the semantics of unbalanced LTSs;

(3) Table 10 shows the difference of the ranking orders between the work in [27] and this paper, which is due to the effect of the innovation in the basic operational laws, the unbalance LTSs, the distance measure and the MULTIMOORA approach proposed in this paper. It can be clearly seen that the method proposed in this paper is an advantages and innovation to solve MAGDM problems over the PHIFLTSs environment.

Table 10. Comparison of results.

\begin{tabular}{cc}
\hline & Ranking \\
\hline Result in [27] & $a_{5}>a_{4}>a_{1}>a_{2}>a_{3}$ \\
Proposed model & $a_{3}>a_{1}>a_{2}>a_{4}>a_{5}$ \\
\hline
\end{tabular}

\subsection{Comparative Analysis from the Numerical Points with HIFLTSs}

For purposes of comparison, the application example presented in Section 7 will be solved based on the TOPSIS method with HIFLTSs, that is to say, the probabilities associated with each linguistic term will be omitted. Then, we can obtain the final ranking as $a_{5}>a_{1}>a_{4}>a_{2}>a_{3}$. Obviously, the difference is due to the effect of probabilities associated with each linguistic term, which verified clearly the importance of the probabilities in the whole process of decision making.

\section{Conclusions}

In this paper, we proposed a new MAGDM model based on the MULTIMOORA approach under the PHIFLTSs environment, which has the following superiorities:

(1) Utilizing the new score function and variance value function of PHIFLTSs makes the comparison between PHIFLEs more accurate and rational;

(2) The unbalanced linguistic term sets were considered during the whole decision processes;

(3) The correlation coefficient of the PHIFLTSs was used to measure the similarity instead of the current distance function in order to alleviate the drawbacks;

(4) The decision results are robustness, simplicity, and effectiveness based on the three aggregation subordinated methods with the use of the extension of the MULTIMOORA approach.

For future research, we shall further analyze the PHIFLTSs in MAGDM problems and extend the proposed methodology to make it apply widely. Modeling the dynamic environment that allows the individual sets of attributes and alternatives is an interesting topic for further discussion. We also want to extend the PHIFLTSs to the probabilistic hesitant intuitionistic fuzzy linguistic preference relation (PHIFLPR), which can be utilized in more extensive decision making situations.

Author Contributions: Conceptualization, Y.P. and Y.T.; Methodology, Y.P. and Y.T.; Formal analysis, Y.P. and Y.T.; Writing-Original Draft, Y.P.; Writing—Review \& Editing, Y.P., Y.T. and B.W.; Validation, Y.T. and X.W.; funding acquisition, Y.P. All authors have read and agreed to the published version of the manuscript.

Funding: This research was supported by the National Social Science Foundation of China (No. 17BGL181), the Natural Science Fund of Heilongjiang Province (QC2015089), and Fundamental Research funds for the Central Universities (307CFW190917).

Conflicts of Interest: The authors declare no conflict of interest.

\section{References}

1. Wu, X.L.; Liao, H.C. A consensus-based probabilistic linguistic gained and lost dominance score method. Eur. J. Oper. Res. 2019, 272, 1017-1027. [CrossRef] 
2. Liao, H.C.; Qin, R.; Gao, C.Y.; Wu, X.L.; Arian, H.K.; Herrera, F. Score-HeDLiSF: A score function of hesitant fuzzy linguistic term set based on hesitant degrees and linguistic scale functions: An application to unbalanced hesitant fuzzy linguistic MULTIMOORA. Inf. Fusion 2019, 48, 39-54. [CrossRef]

3. Zhou, L.; Jin, F.; Chen, H.; Liu, J. Continuous intuitionistic fuzzy ordered weighted distance measure and its application to group decision making. Technol. Econ. Dev. Econ. 2015, 22, 75-99. [CrossRef]

4. Chen, T.-Y. Interval-valued intuitionistic fuzzy QUALIFLEX method with a likelihood-based comparison approach for multiple criteria decision analysis. Inf. Sci. 2014, 261, 149-169. [CrossRef]

5. Wan, S.P.; Dong, J.Y. Interval-valued intuitionistic fuzzy mathematical programming method for hybrid multi-criteria group decision making with interval-valued intuitionistic fuzzy truth degrees. Inf. Fusion 2015, 26, 49-65. [CrossRef]

6. Yue, Z.; Jia, Y. An application of soft computing technique in group decision making under interval-valued intuitionistic fuzzy environment. Appl. Soft Comput. 2013, 13, 2490-2503. [CrossRef]

7. Meng, F.; Zhang, Q.; Cheng, H. Approaches to multiple-criteria group decision making based on interval-valued intuitionistic fuzzy Choquet integral with respect to the generalized $\lambda$-Shapley index. Knowl. Based Syst. 2013, 37, 237-249. [CrossRef]

8. Zhu, J.; Li, Y. Hesitant Fuzzy Linguistic Aggregation Operators Based on the Hamacher t-norm and t-conorm. Symmetry 2018, 10, 189. [CrossRef]

9. Cui, W.; Ye, J. Multiple-Attribute Decision-Making Method Using Similarity Measures of Hesitant Linguistic Neutrosophic Numbers Regarding Least Common Multiple Cardinality. Symmetry 2018, 10, 330. [CrossRef]

10. Liu, D.; Liu, Y.; Chen, X. The New Similarity Measure and Distance Measure of a Hesitant Fuzzy Linguistic Term Set Based on a Linguistic Scale Function. Symmetry 2018, 10, 367. [CrossRef]

11. Dong, Y.; Zhang, H.; Herrera-Viedma, E. Integrating experts' weights generated dynamically into the consensus reaching process and its applications in managing non-cooperative behaviors. Decis. Support Syst. 2016, 84, 1-15. [CrossRef]

12. Morente-Molinera, J.A.; Wu, X.; Morfeq, A.; Al-Hmouz, R.; Herrera-Viedma, E. A novel multi-criteria group decision-making method for heterogeneous and dynamic contexts using multi-granular fuzzy linguistic modelling and consensus measures. Inf. Fusion 2020, 53, 240-250. [CrossRef]

13. Zadeh, L.A. The concept of a linguistic variable and its application to approximate reasoning-Part I. Inf. Sci. 1975, 8, 199-249.

14. Rodriguez, R.M.; Martinez, L.; Herrera, F. Hesitant Fuzzy Linguistic Term Sets for Decision Making. IEEE Trans. Fuzzy Syst. 2011, 20, 109-119. [CrossRef]

15. Liao, H.C.; Xu, Z.S.; Zeng, X.J. Distance and similarity measures for hesitant fuzzy linguistic term sets and their application in multi-criteria decision making. Inf. Sci. 2014, 271, 125-142. [CrossRef]

16. Wei, C.P.; Zhao, N.; Tang, X.J. Operators and Comparisons of Hesitant Fuzzy Linguistic Term Sets. IEEE Trans. Fuzzy Syst. 2013, 22, 575-585. [CrossRef]

17. Liu, H.B.; Rodríguez, R.M. A fuzzy envelope for hesitant fuzzy linguistic term set and its application to multi-criteria decision making. Inf. Sci. 2014, 258, 220-238.

18. Hesamian, G.; Shams, M. Measuring Similarity and Ordering based on Hesitant Fuzzy Linguistic Term Sets. J. Intell. Fuzzy Syst. 2015, 28, 983-990. [CrossRef]

19. Liao, H.C.; Xu, Z.S.; Zeng, X.J.; Merigó, J.M. Qualitative decision making with correlation coefficients of hesitantfuzzy linguistic term sets. Knowl. Based Syst. 2015, 76, 127-138.

20. Liao, H.C.; Gou, X.J.; Xu, Z.S.; Zeng, X.J. Hesitancy degree-based correlation measures for hesitant fuzzy linguistic term sets and their applications in multiple criteria decision making. Inf. Sci. 2020, 508, 275-292. [CrossRef]

21. Zhu, B.; Xu, Z. Consistency Measures for Hesitant Fuzzy Linguistic Preference Relations. IEEE Trans. Fuzzy Syst. 2014, 22, 35-45. [CrossRef]

22. Pang, Q.; Wang, H.; Xu, Z. Probabilistic linguistic term sets in multi-attribute group decision making. Inf. Sci. 2016, 369, 128-143. [CrossRef]

23. Wu, X.L.; Liao, H.C.; Xu, Z.S. Probabilistic Linguistic MULTIMOORA: A Multicriteria Decision Making Method Based on the Probabilistic Linguistic Expectation Function and the Improved Borda Rule. IEEE Trans. Fuzzy Syst. 2018, 26, 3688-3702. [CrossRef]

24. Zhang, Y.; Xu, Z.; Wang, H.; Liao, H. Consistency-based risk assessment with probabilistic linguistic preference relation. Appl. Soft Comput. 2016, 49, 817-833. [CrossRef] 
25. Zhang, Y.X.; Xu, Z.S.; Liao, H.C. A consensus process for group decision making with probabilistic linguistic preference relations. Inf. Sci. 2017, 414, 260-275. [CrossRef]

26. Liao, H.C.; Jiang, L.S.; Xu, J.Z.S.; Xu, P.; Herrera, F. A probabilistic linguistic linear programming method in hesitant qualitative multiple criteria decision making. Inf. Sci. 2017, 415, 341-355.

27. Abbas, M.G.; Bashir, Z.; Rashid, T.; Ali, J. Probabilistic Hesitant Intuitionistic Linguistic Term Sets in Multi-Attribute Group Decision Making. Symmetry 2018, 10, 392. [CrossRef]

28. Kahneman, D. A perspectiveon judgment and choice. Am. Psychol. 2003, 58, 697-720.

29. Torra, V. Negation functions based semantics for ordered linguistic labels. Int. J. Intell. Syst. 1998, 11, 975-988. [CrossRef]

30. Herrera, F.; Herrera-Viedma, E.; Martinez, L. A Fuzzy Linguistic Methodology to Deal with Unbalanced Linguistic Term Sets. IEEE Trans. Fuzzy Syst. 2008, 16, 354-370. [CrossRef]

31. Xu, Z.S. Multi-period multi-attribute group decision-making under linguistic assessments. Int. J. Gen. Syst. 2009, 38, 823-850. [CrossRef]

32. Abchir, M.A.; Truck, I. Towards an extension of the 2-tuplelinguistic model to deal with unbalanced linguistic term sets. Kybernetika 2013, 49, 164-180.

33. Jiang, L.; Liu, H.B.; Cai, J.F. The power average operator for unbalanced linguistic term sets. Inf. Fusion 2015, 22, 85-94. [CrossRef]

34. Zhou, W.; Xu, Z.S. Generalized asymmetric linguistic term set and its application to qualitative decision making involving risk appetites. Eur. J. Oper. Res. 2016, 254, 610-621. [CrossRef]

35. Pei, Z.; Zheng, L. New unbalanced linguistic scale sets: The linguistic information representations and applications. Comput. Ind. Eng. 2017, 105, 377-390. [CrossRef]

36. Cai, M.; Gong, Z.W. Group decision making using distances between unbalanced linguistic assessments. Appl. Soft Comput. 2018, 67, 613-624. [CrossRef]

37. Dong, Y.C.; Li, C.C.; Herrera, F. Connecting the linguistic hierarchy and the numerical scale for the 2-tuplelinguistic model and its use to deal with hesitant unbalanced linguistic information. Inf. Sci. 2016, 367, 259-278.

38. Brauers, W.K.M.; Zavadskas, E.K. The MOORA method and its application to privatization in a transition economy. Control Cybern. 2006, 35, 445-469.

39. Brauers, W.K.M.; Zavadskas, E.K. Project management by MULTIMOORA as an instrument for transition economies. Ukio Technologinis Ir Ekonominis Vystymas 2010, 16, 5-24.

40. Brauers, W.K.M.; Zavadskas, E.K. Robustness of MULTIMOORA: A Method for Multi-Objective Optimization. Informatica 2012, 23, 1-25. [CrossRef]

41. Chakraborty, S. Applications of the MOORA method for decision making in manufacturing environment. Int. J. Adv. Manuf. Technol. 2011, 54, 1155-1166. [CrossRef]

42. Gou, X.J.; Xu, Z.S. Novel basic operational laws for linguistic terms, hesitant fuzzy linguistic term sets and probabilistic linguistic term sets. Inf. Sci. 2016, 372, 407-427. [CrossRef]

43. Wang, J.Q.; Wu, J.T.; Wang, J.H.; Zhang, Y.; Chen, X.H. Interval-valued hesitant fuzzy linguistic sets and their applications in multi-criteria decision-making problems. Inf. Sci. 2014, 288, 55-72. [CrossRef]

44. Zhang, R.C.; Li, Z.M.; Liao, H.C. Multiple-attribute decision-making method based on the correlation coefficient between dual hesitant fuzzy linguistic term sets. Knowl. Based Syst. 2018, 159, 186-192. [CrossRef]

45. Gou, X.J.; Liao, H.C.; Wang, X.X.; Xu, Z.S.; Herrera, F. Consensus based on multiplicative consistent double hierarchy linguistic preferences: Venture capital in real estate market. Int. J. Strateg. Prop. Manag. 2019, 24, 1-23. [CrossRef]

46. Gerstenkorn, T.; Manko, J. Correlation of intuitionistic fuzzy sets. Fuzzy Sets Syst. 1991, 44, 39-43. [CrossRef]

47. Beg, I.; Rashid, T. Hesitant intuitionistic fuzzy linguistic term sets. Notes Intuit. Fuzzy Sets 2014, 20, 53-64.

Publisher's Note: MDPI stays neutral with regard to jurisdictional claims in published maps and institutional affiliations. 